\title{
Zur Kenntnis einiger Alpenseen ${ }^{1}$.

\author{
Von \\ o. Haempel (Wien).
}

II.

Der Grundlsee.

Mit 6 Textfiguren.

\section{Hydrographie.}

A. Lage, Uferentwicklung; $\mathrm{Zu}$ - und Abflüsse des Sees.

Der Grundlsee, wegen seiner schönen Lage gut bekannt, liegt im Lande Steiermark und zählt zu den Seen des Traungebietes. Fr bildet die Fortsetzung des kleineren 'loplitzsees und ist ein ausgesprochener. Talsee. Zwar findet sich bis zum Orte "Wiener" zwischen See und siidlicher Talwandung - ich folge hier den Angaben Müllners - ein flaches Gelände vor, aber westsüdwestlich dieses Ortes ragt $1233 \mathrm{~m}$ hoch das Reschenhorn empor, dessen Nordgehänge unter ziemlich beträchtlichem Böschungswinkel direkt gegen den Grundlsee abfallen. Erst nahe dem Ausflusse der Traun aus diesem werden die Ufer wieder flacher. Das Westende des Sees wird von cinem 40-50 m hohen Moränenwalle umschlungen, welchen die Traun durchschneidet. Die Nordufer des Grundlsees werden bis in die Nähe von "Schachner" von einer Fortsetzung der Gößlwand gebildet. Dann mündet der Zimitzbach, welcher tief in das Gebirge eingeschnitten ist und einen beträchtlichen Schuttkegel in den See vorgebaut hat. Weiterhin wird das Nordufer des Grundlsees von ziemlich flachen, moränenbedeckten Gehängen gebildet; erst 5-600 m über dem Seespiegel stellen sich die Steilabstürze des Klamm, -Hundskogels und Backsteins ein.

Der See mißt in seiner Längsachse $5,9 \mathrm{~km}$, seine größte Breite ist zwischen dem Grasberge und der Bucht westlich von "Gößl“" und beträgt etwa $900 \mathrm{~m}$. Fr bedeckt ein Areal von $4,14 \mathrm{~km}^{2}$. Mit Ausnahme zweier Stellen - die eine befindet sich am Nordufer beim "Kreuz", die andere am Südufer, veranlaßt durch den Abfall des Reschenhorns --, fehlen dem Grundlsee unterseeische Abstürze; überall senken sich

$\left.{ }^{1}\right)$ Siehe diese Zeitschrift, Bd. VIII. Heft 3. 1918. 
die Ufer in flacher Schar zur Tiefe. Der mittlere Neigungswinkel aller Wannenwandungen beträgt nur $4^{0}$. Das Volumen des Grundlsees beläuft sich auf 137,5 Millionen Kubikmeter.

Was nun die Zuflüsse des Grundlsees betrifft, so wären in erster Linie der Gößl- und der Stimitzbach zu nennen; ersterer bildet den Abfluß des oben erwähnten Toplitzsees. Als kleinere Bäche und Rinnsaale sind im Norden der Zimitz- und der Mühlbach zu erwähnen. Unterhalb des Ortes Wiener mündet am Südufer der Azbergbach. Alle anderen Gerinne sind während des Sommers ausgetrocknet, kommen daher als stete Zuflüsse nicht in Betracht. Den Abfluß bildet die Traun, die dem Hallstätter See zueilt.

Als besondere Orts- und Orientierungsbezeichnungen des Grundlsees wären zu nennen: am Nordufer der Ort Hopfgarten, der bekannte Gasthof Schrammel, Ort Steinwandel und Rößeln, Gaiswinkel, die Kapelle von Kreuz, Gasthof Ladner und Schachner, am Ostende des Sees der Ort Gößl, am Süidende der Ort Wiener.

\section{B. Beschaffenheit des Seegrundes.}

Ähnlich wie beim Hallstätter See ist das Seebett des Grundlsees von schlamm-Massen erfüllt, die aus einer kaum einen Meter umfassenden Dickenschicht bestehen. Die Farbe des Schlammes umfaßt alle Farbenabstufungen von Grau, doch überwiegt im allgemeinen ein Schmutziggrau. Der Schlamm enthält Schneckenschalen, Insektenlarven, Würmer und Diatomeen (s. Grundfauna und -flora). Er ist ferner reich an pflanzlichem Detritus, der sich aus den Zerfallprodukten von Potamogeton und Chara zusammensetzt und daher stark kalkhaltig ist ${ }^{1}$ ).

\section{Tiefenverhältnisse.}

Über die Tiefenverhältnisse des Grundlsees konnte ich außer der Tsobathen-Karte in dem Richterschen Atlas der österr. Alpenseen in der Literatur keine weiteren Aufzeichnungen vorfinden. Ich selbst habe mit dem Tiefenthermometer nach Prof. Krümmel an rerschicdenen Seestellen einige Lotungen ausgeführt, die im großen und ganzen mit den in Figur 1 wiedergegebenen Tiefenangaben übereinstimmen. Übcrblicken wir dieselben, so geht aus ihnen hervor, daß der Grundlsee keineswegs den sehr tiefen Alpenseen zugezählt werden kann. Seine größte Tiefe ist mit etwa $64 \mathrm{~m}$ gegeben; sie findet sich ungefähr in der vom "Kreuz"

1) Über die Schlammschichtung der profundalen Zone und ihre Besiedelung wird an anderer Stelle im Zusammenhange mit dem Untersuchungsergebnis anderer Seen ausführlich berichtet werden. 
nach dem Reschenhorn auf die Längsachse des Sees gezogenen Vertikalen. Die mittlere Tiefe wurde mit $33,2 \mathrm{~m}$ berechnet. Ganz steile Uferabstürze, wie sie in der Hauptsache der Hallstätter See aufzuweisen hat, fehlen, wie schon oben erwähnt, dem Grundlsee bis auf wenige Stellen vollständig. Die mit Schotterbänken erfüllte Schar geht vielmehr allmählich in die Halde über und ist, wie dies später ausführlich behandelt werden wird für den Fischbestand des Sees von größter Bedeutung.

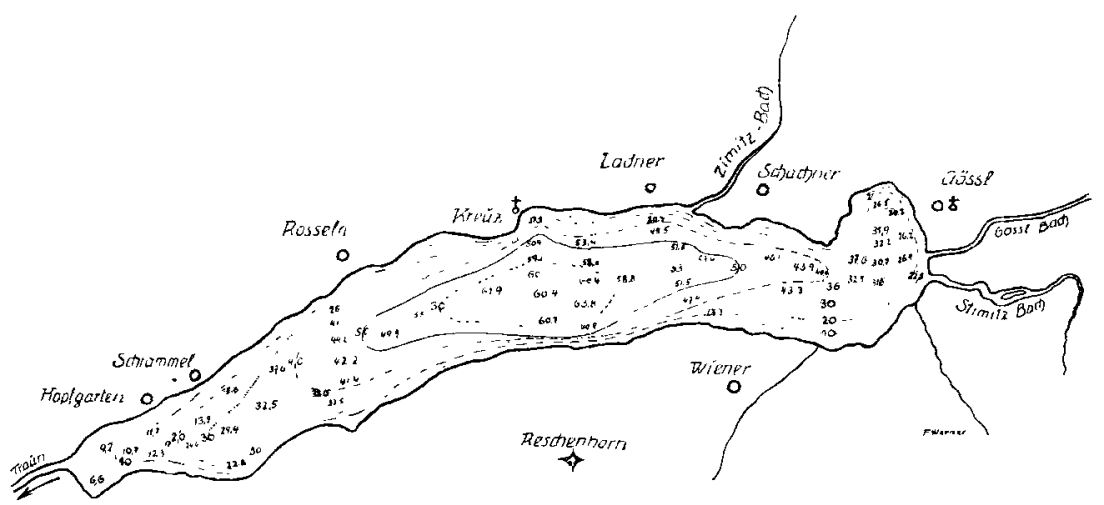

Fig. 1. Tiefenkarte des Grundlsees')

(Aus Richter, Atlas der österr. Alpenseen) etwas schematisiert.

D. Farbe und Durchsichtigkeit.

Der Grundlsee besitzt mit seinem durch den Toplitzsee geklärten Hauptzufluß, dem Gößlbach, mit seinem verhältnismäßig schmalen Bette und mit seinen unbedeutenden, graulichen Dolomit-Detritus führenden Nebenzuflüssen eine blaugrüne Farbe, die in jenen Teilen, wo sich am Seegrunde dichte Charabestände vorfinden, eine dunkelgrüne Nuance annehmen kaun. Im allgemeinen dominiert aber im Vergleich zum Hallstätter See die blaue Farbe vor dem Grün. Erstere hängt wiederum insbesondere ron der. Durchsichtigkeit ab. In dieser Beziehung kann der Grundlsee zu dem mitteldurchsichtigen Alpenseen gerechnet werden. So betrug die Sichtbarkeitsgrenze, welche von mir mittels Secchi-Scheibe am 7. September 1913 festgestellt wurde, $4 \frac{112}{2}-5 \mathrm{~m}$; die Durchsichtigkeit kann demnach mit 9 bzw. $10 \mathrm{~m}$ angenommen werden. Im Winter dürfte sich dieselbe auf $14-16 \mathrm{~m}$ erhöhen.

1) Anmerkung der Redaktion: Durch ein Versehen sind die Textfiguren 1 und 4 zu stark verkleinert worden; wir bitten daher eine Lupe zu Hilfe zu nehmen, wodurch die Zahlen und Bezeichnungen erkennbar werden. 
E. Thermik.

Über die Temperaturverhältnisse des Grundlsees konnte ich in der Literatu keine Angaben vorfinden. In neuerer Zeit sollen rom Wioner geographischen Institut Messungen ausgeführt worden sein, die aber meines Wissens bisher noch nicht publiziert worden sind. Für vorliegende Arbeit wurde der Gang der Oberflächentemperatur des Socwassers während der Jahre 1911 und 1912 monatlich gelegentlich ron Planktontängen seitens der Forst- und Domänenverwaltung „Grundlsee* gemessen und mir zur Verfügung gestellt, wofür ich an dieser stelle meinen besten Dank aussprechen möchte. Die Tiefentemperaturmesiungen wurden von mix selbst mittels des Kippthermometer's nach $K r$ ümmel am 15. September in der tiefsten Seeregion vorgenommen. Die Ergeb-

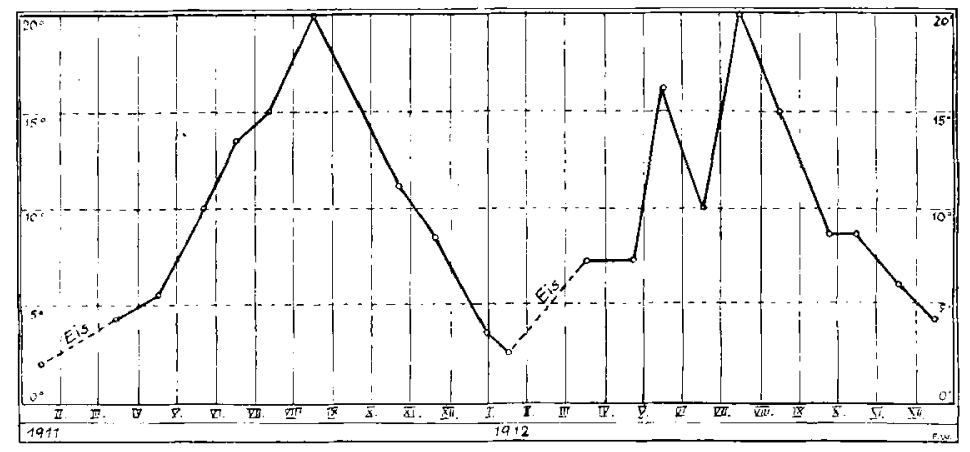

Fig. 2. Gang der Oberfl̈̈chentemperatur des Grundlsees während der Jahre 1911-1912.

nise beider Messungen sind in den 'lextfiguren 2 und 3 graphisch dargestellt. Aus der ersten Kurvendarstellung geht herror, daß das Oberflächenwasser ein Jahresmaximum von $20^{\circ} \mathrm{C}$ erreicht hat, wovon das eine Mitte August 1911, das andere Mitte Juli 1912 fällt. Über dic Minima liegen keine sicheren Daten ror. Mitte Jänner 1911 und 1912 wurden $2^{\circ}$ bzw. 2,50 C gemessen. Dann stellte sich Eisbildung ein, wolche laut Angabe der Forstverwaltung im Jahre 1911 vom 3. Feber bis 15. März und 1912 vom 18. Jämner bis 15. März dauerte. Leider wurden unter dem Eise keine Temperaturen gemessen, so daß die Jahreskurve für diese Zeit eine Unterbrechung erleidet. (In der Figur 2 gestrichelt eingezeichnet.) Da aber bekanntlich das Wasser unmittelbar unter dem Eise die niedrigste 'Temperatur aufweist, so dürfen die Mi-

1) Siehe die Abhandlung über den „Hallstätter See“ in dieser Zeitschrift. 
nima, die zwischen $1^{0}-2^{\prime C} \mathrm{C}$ liegen, in die Monate der Eisbildung (Februar) fallen. Letztere stellt sich in Gegensatz zum Hallstätter See alljäbrlich ein. Als Grund dürfte das Fehlen ron warmen Quellen im Grundlsee angenommen werden. Das geht auch schon daraus hervor, daß das Oberflächenwasser des Hallstätter Sees in den Jalıren 1911 und 1921 Minimaltemperaturen von $3,7^{\circ} \mathrm{bzw} .5^{\circ} \mathrm{C}$ erreichte und eine Fisbildung in diesen Jahren ganz ausblieb. Figur $\mathbf{3}$ gibt den Verlauf der Temperaturabnahme nach der Tiefe nach eigenen Messungen rom 15. Sep-

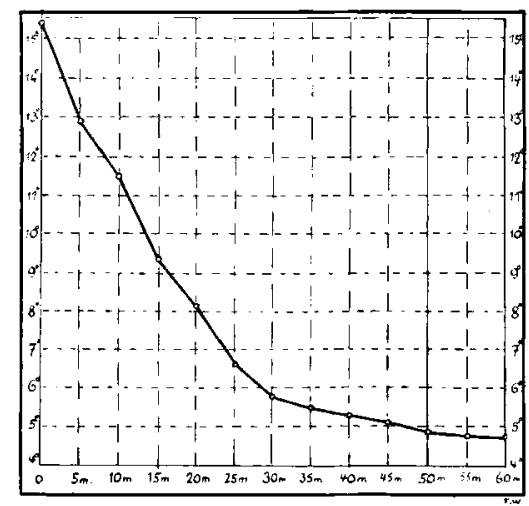

Fig. 3. Verlauf der Tiefentemperatur im Grundlsee nach Messungen vom 15. 9. 1913.

tember 1913 bei einer Lufttemperatur von $19^{\circ} \mathrm{C}$ und bewölktem Himmel. Wie im Hallstätter See, findet sich auch im Grundlsce eine doppelte Sprungschicht angedeutet. Die erste liegt zwischen 3 und $4 \mathrm{~m}$ Tiefe (Tempeperaturdifferenz $1,3^{\circ} \mathrm{C}$ ), die zweite zwischen 10 und $15 \mathrm{~m}$ Tiefe (siehe Figur 2). Was den Verlauf der. Gesamtkurve betrifft, so erkennt man an dem steilen Verlauf derselben zwischen 0 und $30 \mathrm{~m}$ eine rapide $\mathrm{Ab}$ nahme der Temperatur vol $15,5^{\circ} \mathrm{O}$ auf $5,8^{\circ} \mathrm{C}$. Von da an nimmt die Temperaturkurve einen allmählichen Verlauf. Die Temperaturdifferenz von $5 \mathrm{zu} 5 \mathrm{~m}$ bewegt sich zwischen $0,1^{\circ}-0,3^{\circ} \mathrm{C}$. Bei $55 \mathrm{~m}$ 'liefe scheint zur Zeit der Messung die niedrigste lemperatur mit $4,8^{\circ} \mathrm{C}$ gewesen zu sein; denn die gleiche Zahl wurde auch über dem Seegrunde abgelesen.

Schlieblich mögen in einer kurzen Tabelle die Resultate meiner Messungen angeführt werden. 


\begin{tabular}{|c|c|c|c|c|c|c|}
\hline \multicolumn{4}{|c|}{$\begin{array}{l}\text { Monatl. Oberflächentemperatur } \\
\text { während der Jahre }\end{array}$} & \multirow{2}{*}{$\begin{array}{l}\text { Seemitte zwischen } \\
\text { Kreuz u. Reschen- } \\
\text { horn 15./IX. } 1913\end{array}$} & \multirow{2}{*}{\multicolumn{2}{|c|}{$\begin{array}{l}\text { Tiefentemperatur } \\
\text { von } 10-60 \mathrm{~m}\end{array}$}} \\
\hline \multicolumn{2}{|c|}{1911} & \multicolumn{2}{|c|}{1912} & & & \\
\hline$\overline{15 . / \mathrm{I} .}$ & $22^{0} \mathrm{C}$ & 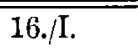 & $2,5^{0} \mathrm{C}$ & Oberfl. $14,8^{\circ} \mathrm{C}$ & $10 \mathrm{~m}$ & $11,5^{\circ} \mathrm{C}$ \\
\hline - & - & - & - & $14,5^{\circ} \mathrm{C}$ & $15 \mathrm{~m}$ & $9,4^{\circ} \mathrm{C}$ \\
\hline - & - & 16./III. & $7,5^{\circ} \mathrm{C}$ & $14,4^{\circ} \mathrm{C}$ & $20 \mathrm{~m}$ & $8,1^{\circ} \mathrm{C}$ \\
\hline 18. IV. & $5,7^{\circ}$ & $23 . / \mathrm{IV}$. & & $3 \mathrm{~m}$ & $25 \mathrm{~m}$ & $6,6^{\circ} \mathrm{C}$ \\
\hline 18. V. & $10^{\circ} \mathrm{C}$ & $15 . / \mathrm{V}$ & $16,2^{\circ} \mathrm{C}$ & $13,0^{\circ} \mathrm{C}$ & $30 \mathrm{~m}$ & $5,8^{\circ} \mathrm{C}$ \\
\hline 13. VI. & $13,7^{\circ} \mathrm{C}$ & 17./VI. & $10^{\circ} \mathrm{C}$ & $12,9^{\circ} \mathrm{C}$ & $35 \mathrm{~m}$ & $5,5^{\circ} \mathrm{C}$ \\
\hline 12./VII. & $15^{\circ} \mathrm{C}$ & 15./VII. & $20^{\circ} \mathrm{C}$ & $6 \mathrm{~m} \cdot 12,7^{\circ} \mathrm{C}$ & $40 \mathrm{~m}$ & $5,3^{\circ} \mathrm{C}$ \\
\hline 17./VIII. & $20^{\circ} \mathrm{C}$ & 15./VIII. & $15^{\circ} \mathrm{C}$ & $7 \mathrm{~m} \quad 12,5^{\circ} \mathrm{C}$ & $45 \mathrm{~m}$ & $5,1^{\circ} \mathrm{C}$ \\
\hline- & - & 23. IX. & $8,7^{\circ} \mathrm{C}$ & $8 \mathrm{~m} \quad 12,3^{\circ} \mathrm{C}$ & $50 \mathrm{~m}$ & $4,9^{\circ} \mathrm{C}$ \\
\hline $20 . / \mathrm{X}$. & $11,2^{\circ} \mathrm{C}$ & 13./X. & $8,7^{\circ} \mathrm{C}$ & $9 \mathrm{~m} \quad 11,7^{\circ} \mathrm{C}$ & $55 \mathrm{~m}$ & $4,8^{\circ} \mathrm{C}$ \\
\hline 17. $\mathrm{XI}$. & $8,7^{\circ} \mathrm{C}$ & 17./XI. & $6,2^{\circ} \mathrm{C}$ & & $60 \mathrm{~m}$ & $4,8^{\circ} \mathrm{C}$ \\
\hline 28./XII & $3,7^{\circ} \mathrm{C}$ & 17./XII. & $4,3^{\circ} \mathrm{C}$ & & $62 n$ & $4,8^{\circ} \mathrm{C}$ \\
\hline
\end{tabular}

F. Die chemische Zusammensetzung des Seewassers.

Die chemische Zusammensetzung des Seewassers hängt in erster Linie von der Beschaffenheit der Zuflüsse ab. In zweiter Linie beeinflußt das Seebecken selbst, seine Tiefe, seine Flora und Fauna, dieselbe. Für den Grundlsee steht mir eine Analyse zu Gebote, welche, wie beim Hallstätter See, Herr Dr. Alexander (Wien) auszuführen die Liebenswürdigkeit hatte. Ihm möchte ich an dieser Stelle meinen besten Dank sagen. Im nachfolgenden sei das Ergebnis der Analyse angeführt.

Einzelbestandteile in 1 Liter Seewasser in Milligramm.

Grundlsee

Gesamtrückstand 114,0

Glührüickstand $\quad 65,0$

Organ. Substanz 49,0

Calciumoxyd $\quad 62,5$

Magnesiumoxyd $\quad 1,0$

Caliumoxyd $\quad 2,0$

Natriumoxyd $\quad 2,6$

Schwefelsäure $\quad 1,0$
Hallstätter See

123,0

75,0

48,0

63,2

1,9

3,2

4,6

Vergleicht man obige Zahlen mit jenen des Hallstätter Sees, so herrscht im großen und ganzen eine große Ähnlichkeit in der Zusammersetzung. Auffallend und nicht recht zu erklären ist im Grundlsee der hohe Gehalt an organischer Substanz, da im allgemeinen in Alpen-Seen die Gesamtmenge der organischen Bestandteile selten $10-20 \mathrm{mg}$ im Liter zu überschreiten pflegt. 


\section{Hydrobiologie des Grundlsees.}

A. Die Organismen des Litorale.

a) Die Flora.

Da für einen mehr oder weniger reichen Bestand an Litoralfauna in erster Linie die höheren Wasserpflanzen ausschlaggebend sind, soll zunächst die Litoralflora des Grundlsees in ihrer ïkologischen Verbreitung tiner näheren Besprechung unterzogen werden. Zur Erläuterung diene die beigegebene Ufervegetationskarte (s. Figur 4), welche ron mir nach Aufnahmen rom 7. September 1913 entworfen wurde.

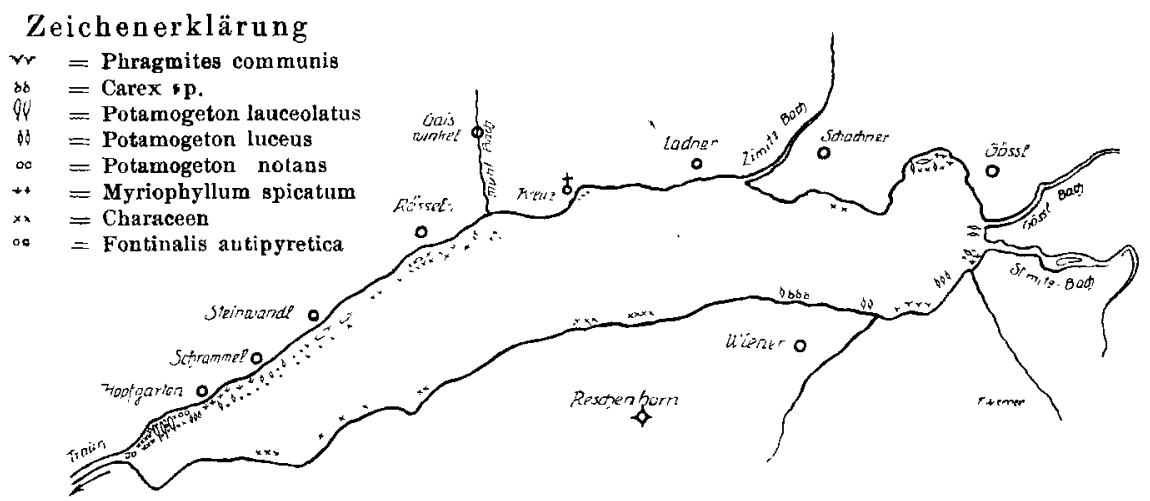

Fig. 4. Ufervegetationskarte des Grundlsees.

Wie der Hallstätter See, ja in noch viel höherem Maße gehört der Grundlsee zu den regetationsarmen Alpenseen, soweit wenigstens die Phanerogamen in Betracht kommen. Werden doch, wie früher angeführt wurde, die Ufer meist von flachen, moränenbedeckten Schotter-Gelä̈ngen gebildet, die eine üppige Fntfaltung der höheren Flora rerhindern. Auch die Artenzahl der höheren Pflanzen ist eine sehr geringe; sie umfaßt nur 7 Spezies. Es sind dies eine uferliebende, nicht näher bestimmte Carexart, ferner Phragmites communis Tr., Potamogeton lanceolatus L., Potamogeton lucens L. und Potamogeton natans L., Myriophyllum spicatum L. und Fontinalis antipyretica. Ausgedehnte unterirdische Bestände bilden dagegen die den Kryptogamen zugezählten Characeen, von denen zwei Arten, nämlich Chara fragilis De. und Chara aspera W., dem See angehören.

Im nachfolgenden will ich nunmehr rersuchen, nach meinen Aufzeichnungen vom 7. September 1913 ein ungefähres Ufervegetationsbild des Grundlsees zu geben. Am westlichen Ende des Sees, wo die Traun 
sich anschickt, den See zu verlasson, findet sich in der starken $t$ bströmung eine typisch flutende Flora, bestehend aus Fontinalis antipyretica und Potamogeton lanceolatus, letztere Pflanze in Anpassung an das starke Rinnen mit sehr schmalen, in die Länge gezogenen Blättern. Zwischen den beiden genannten Pflanzen hat, wie hier nur kurz bomerkt sei, die Bachforelle des Sees ihren Standort. Verfolgen wir das Nordufer des Sees von den ärarischen Fischhütten aus, so sehen wir die flache Schar zunächst mit Fontinalis, Potamogeton lanceolatus und einem dichten Rasen ron Chara bewachsen. Dazwischen stehen vereinzelt 3-4 m hohe Bestände ron Potamogeton lucens; mehr dem Ufer zu ist ferner ganz sporadisch Potamogeton natans anzutreffen. Zwischen „Hopfgarten“ und ,Schrammel" finden sich dann größer' Ansiedlungen ron Potamogeton lucens und Myriophyllum spicatum. Hinter ,Steinwandl" folgt eine nackte Geröllzone, die nur: spärlich von Chara bewachsen ist. In der Nähe von „Rösseln" wird der submerse Charabestand wieder ein sehr dichter; hier findet sich eine besonders schöne Uferschar ausgebildet. Hinter "Rösseln" wird die Schar wieder von nackten Schotterbïnken gebildet. Bei "Gaiswinkel" setzt die Charawiese wieder ein, sich nunmehr bis zur Einmündung des Mühlbaches von Gaiswinkel hinziehend. Im Mündungsgebiete desselbon ist eine Schotterbank entstanden, welche einen der bekannten Laichplätze des Seesaiblings bildet.

In der Bucht von "Kreuz" taucht für kurze Zeit Chara wieder auf, um dann für das Auge des Beschaners für längere Zeit vollständig zu verschwinden. Hier stürat ja auch das Ufer mit steiler Halde in die Tiefe. Vor dem "Ladner" werden indes wieder seichte Schotterbänke sichtbar, die frei von jeglichem Pflanzenwuchse sind. Die gleichen Verhältnisse weist das Ufer bei Einmündung des Zimitzbaches auf. Hier soll sich nach Aussage der Grundlsee-Fischer ein zweiter Laichplatz der Seesaiblinge befinden. Zu erwähnen wäre ferner, dab in der Nähe des ,Schachner" das Betriebswasser einer Säge in den See mündet, welches eine Menge Holzstaub (Sägemehl) dem See zuführt, wodurch die UferSchotterbank anf eine längere Strecke rerschlickt. Die Finleitung eines derartigen Verunreinigungsstoffes sollte auf alle Fälle untersagt werden. Einen reicheren Bestand von Pflanzen hat die "GöBl-Bucht" aufzuweisen. Wir finden hier nämlich gemischte Ansiedlungen von Potamogeton lanceolatus, Potamogeton lucens und Myriophyllum spicatum. Außerdem seewärts ausgedehnte submerse Teppiche ron Chara, die dem Seewasser, vom Kahne aus botrachtet, ein graugrünes Aussehen verleihen. Das Ostufer des Sees ist im allgemeinen florenarm. Zwischen Gößl- und 
Stimitzbach gedeiht in lockeren Beständen Potamogeton lucens. Hinter der Einmündung des Stimitzbaches desgleichen Potamogeton lucens und Myriophyllum spicatum; mehr seewärts dagegen Chara. Wenden wir uns nummehr dem Südufer zu. Im Vergleich zum Nordufer ist dasselbe, trotzdem meistens eine sanft abfallende schar ausgebildet ist, bedeutend ärmer an Flora. Eine Erklärung findet diese Erscheinung dadurch, daß auf Schar und Halde große sterile Geröllmassen lagern. Vor dem Orte "Wiener" findet sich die einzige Uferstelle des Sees, die mit einer Carex-Art und Phragmites communis bewachsen ist, der Schilfgürtel ist indes auch hier sehr schmal und schütter. An diesen grenzt hierauf ein kurzer submerser Streifen von Potamogeton lucens. Auch beim Orte „Wjener" ist ein solcher zu ersehen. Nun folgt eine längere Strecke nackten Ufergeländes. Über demselben breiten sich landeinwärts flachgeneigte Wiesen aus, die dem See ihr Sickerwasser zusenden, wodurch derselbe gleichzeitig eine gewisse Düngung erhält. Auf das kahle Gelände folgt eine kurze Strecke ein dichter Bestand von Chara. Danm wird das Ufer sehr steil und erinnert vielfach an jenes rom Hallstätter See. Es sind die Ausläufer des Reschenhorns, die felsartig in steiler Halde in die Tiefe stürzen. Bald verflacht sich indes wieder das Ufer, ohne aber eine Vegetation aufzuweisen. Schar und Halde sind auch hier mit massigem Gesteinsgeröll überlagert; hier soll sich dor beste Laichplatz der Seesaiblinge vorfinden. Die ersten Spuren einer Vegetation erblickt man wieder erst in einer kleinen Bucht, die sich gegenüber von „Rösseln" vorfindet. Hier breitet sich wieder Chara in dichten Polstern ans. Auch der Rest des Südufers läßt diese Pflanze überall erkennen, mit Ausnahme der gegenüber "Schrammel" liegenden seichten und schlammigen Bucht, welche vollkommen regetationslos ist.

Erscheint mit obiger Beschreibung die höhere Flora (inbegriffen der Characeen) erschöpft, so müssen auch die Kryptogamen noch erwähnt werden. Untersuchungsproben standen mir aus der Bucht von "Gößl" und dem Nord- und Südufer zur Verfügung. Zwischen und an dem Steingerölle der Uferbänke haften oft große Watten von Spirogyren (Zygnema stellinum Ag.) und Oscillatorien. Krustenbildungen wie im Hallstïtter See fehlen dagegen vollständig. Im Schlamm und Sande des seichten. Ufers fanden sich ferner folgende Formen vor: Merismopedia glauca Naeg., Scenedesmus obliquus Ktzg., Pediastrum duplex M., Cosmarium botrytis Menegt., Gloeotrichia echinulata Richt., Rhaphidium polymorpbum Fres., Pleurosigma acuminatum Grun., Synedra acus Grun., Fragillaria virescens Ralfs, Surirella splendida $\mathrm{Kg}$. 
Überblickt man nochmals den Florenbestand des Grundlsees, so mul\} derselbe in der Tat als arm bezeichnet werden. War es für den Hallstätter See auf Grund seines Macrophytenbestandes noch möglich, eine Zoneneinteilung des Litorale zu schaffen, so ist dies für den Grundlsee nicht der Fall. Es nähert sich vielmehr dieser see den Verhältnissen, wie sie der Faistenauer Hintersee besitzt. Micoletzky (5) hat für diesen See vier Litoralzonen aufgestellt: Fazies des groben Gerölls, Fazies des Schlammes, Fazies der Charawiesen und Fazies der 'Tiefenregion. In ganz ähnlicher Weise läßt sich der Grundlsee behandeln und möchte ich hier: folgende Zoneneinteilung aufstellen: 1. Zone des Gerölls, 2. Zone des Potamogeton (Potamogetonetum), 3. Zone der Charawiesen (Characetum). Mit diesen drei Zonen ist das Litorale des Grundlsees vollständig charakterisiert und erübrigt sich eine besondere Beschreibung desselben.

b) Fauna (Litoral- und Bodenfauna).

Die Ufer des Grundlsees wurden von mir am 7. September 1913 befahren und vom Kahne aus mittels Netz und Dredge an verschiedenen Stellen Proben gesanmelt, welche eine reiche Auslese ron Litoraltieren ergaben. Bei der Bestimmung der Tiefenformen waren mir abermals die Herren Kollegen 'Thienemann und Micoletzky behilflich. Ersterer übermahm die Tendipediden, letzterer die Nematoden (6). Beidon Herren möchte ich auch an dieser Stelle meinen besten Dank für ihre Mühewaltung aussprechen. Herrn Professor Klapálek verdanke ich ferner die Bestimmung der Trichopteren-Larven. Über die Fauna des Grundlsees ist meines Wissens im Zusammenlange bisher nichts publiziert worden, es gehört dieser See demmach zu den faunistisch wenig bekannten Becken. Tereinzelte Angaben speziell über Cladoceren dieses Sees finden sich nur in einer Arbeit ron Langhans (4). Dieser beschreibt aus der sog. Koelbelschen Sammlung sowie auf Grund eigener Fänge verschiedene Spezies und knïpt daran einige Bemerkungen biologischer Natur. Jene Cladoceren-Formen, welche bereits Langhans vorgefunden hat, sind im nachfolgenden Verzeichnisse mit einem * bezeichnet.

Protozoa:

Amoeba proteus Lesdig

Arcella vulgaris Ehrbg.

Difflugia acuminata Ehrbg.

Diffilugia globulosa Duj.

Centropyxis aculeata Stein

Codonella lacustris Entz 
Hydrozoa:

Turbellaria:

Rotatoria:

Oligochaeta:

Hirudinea:

Nematodes:

Copepoda:

Phyllopoda:

Ostracoda:
Hyclra vulgaris Pall.

Dendrocoelum lacteum Oerst.

Dallyellia sp. Flem.

Planaria sp.

Noteus quadricornis Ehrbg.

Rotifer vulgaris Schr.

Stylaria lacustris L.

Chaetogaster diaphanus Gr.

Aeolosoma sp. Ehrbg.

Herpobdella atomaria Car.

Glossosiphonia complanata L.

Chromadora bioculata M. Schultze

Alaimus primitivus de Man

Aphanolaimus aquaticus Daday

Tripyla papillata Bütschli

Cylindrolaimus aberrans n. sp.

Plectus cirratus Bastian

Dorylaimus bastiani Bütschli

Dorylaimus carteri Bastian

Tylenchus dubius Bütschli

Cyclops fuseus Jur.

Cyclops serrulatus Fischer

Cyclops viridis Jur.

Canthocamptus wierzejskii Mrazek

* Simocephalus vetulus (0. F. Müller)

* Sida crystallina (O. F. Müller)

Alona quadrangularis (O. F. Müller)

* Alona costata G. O. Sars.

* Alonopsis elongata G. O. Sars.

* Acroperus harpae Baird.

* Eurycercus lamellatus (O. F. Müller)

* Scapholebris mucronata (O. F. Müller)

* Peracantha truncata (O. F. Müller)

* Graptolebris testudinaria (S. Fischer)

* Pleuroxus bairdi var. uncinatus Baird.

Chydorus sphaericus (O. F. Müller)

Cyclocypris laevis (O. F. Müller)

Candona candida (O. F. Müller) 


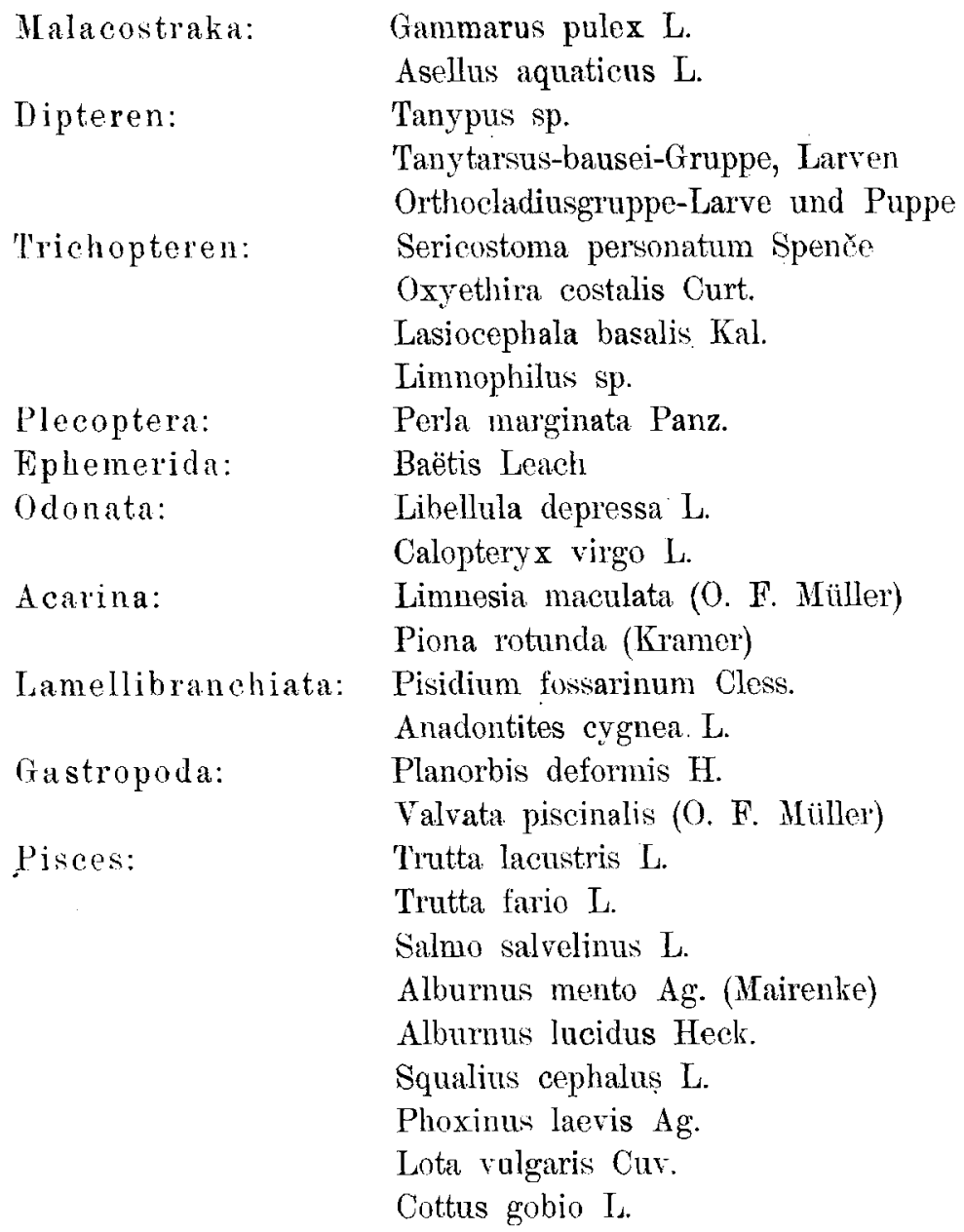

Amphibien, Reptilien und Aves blieben unberücksichtigt.

Das Verzeichnis enthält 73 Arten, kann aber, da es sich um eine einmalige Probeentnahme handelt, natürlich keinen Anspruch auf Vollständigkeit machen. Die angegebene /ahl ließe sich bei oftmaliger Untersuchung sicherlich auf 100 erhöhen. Auch im Grundlsee wurden die Untersuchungen in fischereilich-biologischem. Sinne ausgeführt und moist nur die größeren Tierformen, welche als Nahrung der Fische in Betracht kommen, berücksichtigt. Doch genügen auch diese, um uns einen Einblick in die verschiedenen Biocoenosen zu geben. -

Bei Besprechung der Seeflora stellte ich für das Litorale des Grundlsees drei Zonen auf, nämlich die des steinigen Geröls, dic des Potamo- 
geton und die der Charawiesen. Die gleiche Einteilung kann num auch für die Tierwelt des Litorale angewandt werden. Im nachfolgenden sei eine kurze Charakteristik der Tier-Biocoenosen dieser Seezonen gegeben.

\section{Zone des steinigen Gerölls.}

Diese Zone umsäumt mit sanfter Schar und Halde fast den ganzen See; nur zwei Stellen, bei "Kreuz" und am Reschenhorn, machen daron eine Ausnahme, indem hier massige Felsen tief in den See abstürzen. Sonst ist die seichte Schar überall mit Gerölle, das Steine von Haselnußbis Kindskopfgröße enthält, angefüllt. Arm an Wasserpflanzen, wird diese Zone im Sommer ron den Sonnenstrahlen gut durchwärmt und bildet den Lieblingsaufenthalt vieler Cypriniden, wie Lauben, Pfrillen u. a. Da die Zone im äbrigen dem Wellenschlage hart ausgesetzt ist, finden wir ähnlich wie im Hallstätter See in der niederen Fauna einerseits Formen, die sich mittels besonderer Kriechsohlen, Saugnäpfen, durch Abflachung des Körpers usw. an diese besonderen Verhältnisse angepaßt haben: Hṛdra, Dendrocoelum, Planaria, Glossosiphonia, Rotifer u. a. Da aber andererseits die zwischen den Gerölsteinen befindlichen engen Risse und Zwischenräume den Tieren genügenden Schutz gegen das Hinweggespült-Werden gewähren, kommen auch Formen vor, die nicht besondere Verankerungsrorrichtungen besitzen, wie die Wasserasseln und die Flohkrebse. Auch niedere Krustaceen, wie Cyclops serrulatus, bewohnen das steinige vegetationsarme Ufer. Von Tendipediden sind die Larven der Orthocladiusgruppe die häufigsten. Von Insektenlarven sind ferner Perla marginata und Baëtis Leach unter Steinen häutig anzutreffen. Desgleichen findet man am unteren Scharabfaile die Schnecken Planorbis und Valrata in zahlreichen Exemplaren. Besonders augenfällig war aber im September 1913 das kolossale Auftreten der Phraganide Sericostoma personatum. Es gab Stellen, an denen man diese Larven in die Tausende zählen konnte.

\section{Zone des Laichkrautes (Potamogetonetum).}

$\mathrm{Zu}$ dieser rechne ich jene Vegetationszone, welche von Potamogeton (als Leitpflanze) und Myriophyllum gebildet wird. Auch der unbewachsene seichte Schlammgrund muß dieser Region zugezählt werden. In bezug auf niedere Fauna ist diese Zone erheblich reichhaltiger als die steinige Uferzone. Den ausschlaggebendsten Unterschied in der 7usammensetzung beider Orthichkeiten bildet das zahlreiche Auftreten der Cladoceren und Tendipediden. Das durch Abkäschern von Potamogeton und Myriophyllum gewonnene Material enthielt fast alle die in Ver- 
zeichnisse angeführten Kruster, wobei quantitativ Sida crystallina in den Vordergrund tritt. Diese äulerst durchsichtige Cladocere sitzt mittels ihres Haftorganes in großer Zahl an der Unterseite der PotamogetonBlätter. Hier ist auch Simocephalus vetulus häufig anzutreffen. Ebenso der Lynceide Acroperus harpae, welcher, wie schon Langhans (4) herrorhob, in den beiden Varietäten harpae und angustatus vorkommt. Neben Krustern ist anch der Aufwuchs an Dipterenlarven, besonders ans der Orthocladiusgruppe, ein bedeutender.

Sehließlich möchte ich an dieser Stelle der Fauna des Ufer-Schlammes gedenken. Während die Cladoceren nur spärlich sind, finden wir hier Vertreter aus der Gruppe der Würmer, der Oligochaeten und insbesondere der Nematoden. Von ersteren wären Chaetogaster diaphanus und Aeolosoma zu nennen. Von Nematoden sind nach Micoletzky als typische Schlammbewohner Chromodora bioculata, Tylenchus dubius, Tripyla papillata, Dorylaimus bastiani und Cylindrolaimus aberrans zu nennen. Chromodora bioculata ist ähnlich wie im Faistenauer. Hintersee als häufigste Art die Leitform im Grundlsee. Tylenchus dubius ist sonst eine terricole Art, die bisher für das Süßwasser noch nicht nachgewiesen wurde. Ganz neu und bisher in den Ostalpen noch nicht aufgefunden ist das Genus Cylindrolaimus. Die vorliegende Art C. aberrans leitet nach Micoletzky zu Plectus hinüber. „So besitzt sie eine mit zerstreuten Borsten versehene, eine deutliche Seitenmembran tragende Cuticula mit komplizierter Schichtung und Querringelung, einen deutlich doppelt konturierten Exkretionsporus, der in einen plectusartig gewundenen Excretionskanal übergeht; ferner sind die Seitenorgane nicht geschlossen und kreisförmig, sondern hinten offen und erinnern dadurch gleichfalls an zahlreiche Plectusarten. Der klappenlose Bulbus ist groß und muskelkräftig, die Ovarien sind paarig symmetrisch mit großem Umschlag" (Micoletzky laut schriftlicher Mittcilung). Neben Würmern sind auch die Ostracoden mit Cyclocypris laevis und Candona candida häufig rertreten. Ton Mollusken müssen Planorbis deformis und Anadontites cygnea, letztere aufrecht im Schlamme steckend, erwähnt werden. Sehließlich sei der Vollständigkeit halber das Vorkommen der limikolen Amoeben, Amoeba proteus, Arcella vulgaris, Difflugia globulosa und acuminata und Centropyxis aculeata hervorgehoben.

\section{Zone der Charawiesen.}

Diese Zone, in der auch noch das Quellmoos Fontinalis antipyretica häufig ist, reicht im Grundlsee bis $15 \mathrm{~m}$ Tiefe. Eine Trennung in eine Zone der seichten und eine solche der tiefen Charawiesen, wie sie 
Micoletzky (5) für den Faistenaner Hintersee aufstellt, schien mir hier nicht durchführbar, zumal Unterschiede in der Zusammensetzung der niederen Fauna nicht oder nur in geringem Maße zu konstatieren waren. Im allgemeinen kann gesagt werden, daß faunistisch am ergiebigsten wohl die Charazone bezeichnet werden muß. Sie zeichnet sich besonders durch ihren Reichtum an Würmern, Dipteren, Phryganiden und Mollusken aus. Von Oligochaeten sind wiederum die schon oben genannten Arten vertreten; merkwürdigerweise fehlt der. Tubifex hier vollständig. Von Hirudineen sind häufig anzutreffen Herpobdella atomaria und Glossosiphonia complanata. Sebr zablreich sind ferner die Oligochaeten mit 6 Arten Chromadora bioculata, Aphanolaimus aquaticas, Alaimus primitivus, Plectus cirratus, Dorylaimus bastiani und carteri. Zwischen und an den Fontinalisblättern findet man ferner in großen Mengen die zierlichen Gehäuse von Tanytarsus-Larven der Bauseigruppe, sowie jene der Phryganiden Oxyethira und Lasiocephala basalis. Im CharaGewirr sind ferner große Mengen von Mollusken, nämlich Valvata piscinalis und Pisidium fossarinum anzutreffen. Von Krustaceen sind besonders Copepoden-Arten häufig. Aber auch die Phyllopoden mit Acroperus harpae, Grabtolebris testudinaria und Chydorus sphaericus fehlen nicht. Im Fontinalis-Blättergewirr konnten fèrner alte und juvenile. Tiere von Gammarus pulex und Asellus aquaticus häufig aufgefunden werden. Ähnlich wie im Hallstätter See sind schließlich für die Charavegetation die Acarinen charakteristisch; sie sind mit Piona rotunda und Limnesia maculata stets vertreten.

\section{B. Die Organismen der Tiefe.}

Die Tiefen- oder profundale Region $(20-60 \mathrm{~m})$ umfaßt den Seegrund im engeren Sinne des Wortes. Derselbe besteht im Grundlsee aus einem humuslehmigen Schlick von dunkelgrauer Farbe. Seine Hauptmasse bilden Reste abgestorbener Pflanzengewebe (Detritus) nebst tierischen Bestandteilen. Die Reichhaltigkeit an lebender Fauna und Flora ist im Vergleiche zur Litoralregion eine sehr geringe. Eine Grundalgenzone konnte nicht festgestellt werden, wenngleich mit dem Schlamme zahlreiche Fäden von Zygnema stellinum und Oedogonium zutage gefördert werden konnten. Dafür enthält der Schlamm zahlreiche Diatomeen, wie Pleurosigma attenuatum W. Sm, Surirella biseriata Brab., Cymbella affinis Kütz, Amphora affinis Kg., Diatoma elongatum Grun. und Nitzsehia spectabilis W. Sm. Die Fauna des Seekessels, die ich mit Dredge aus einer Tiefe von $40 \mathrm{~m}$ heraufholte, ist eine arten- und individuenarme. Die Kom- 
ponenten derselben bilden Protozoen, Würmer, Copepoden, Dipteren und Mollusken, die verhältnismäßig nur wenige typische Tiefenbewohner stellen. Von Protozoen finden sich Difflugia globulosa und Centropyxis acullata, ron Turbellarien Dendrocoelum lacteum nebst einer unbestimmbaren Planarie, die aber sicherlich nicht $P$. alpina ist. Daß der in der Tiefe sonst überall vorkommende Tubifex nicht festgestellt werden konnte, wurde bereits oben erwälnt. Von Nematoden konnten als TiefenSchlammbewohncr Aphanolaimus aquaticus und Dorylaimus bastiani aufgefunden werden. Die Copepoden sind durch zwei Cyclops-Arten vertreten, durch C. viridis und C. fuscus. Ob Canthocamptus Wierzejskii ebenfalls vorkonmt, konnte an dem einzigen erbeuteten Kxemplare nicht mit großer Sicherheit ermittelt werden. Von Ostracoden beobachtete ich Cyelocypris laevis und Candona candida. Daneben kriechen im Schlamme die Wasserasseln herum. Stark verbreitet sind im Grundlsee auch in der Tiefe die oben namhaft gemachten Dipteren-Formen; sie spielen, wie dies noch später im fischereilichen Abschnitte näher erörtert werden wird, auch in diesem See bei der Ernährung des Saiblings eine nicht unbedoutende Rolle. Ton Mollusken ist Pisidium fossarinnm am häufigsten vertreten, daneben auch Valvata piscinalis recht zahlreich. Letztere ist indes im Grundsee mehr eine Litoralform und stellenweise rom da in die Tiefe eingewandert.

Mit dieser Aufzählung ist die Tiefenfama des Grundlsces erschöpft ${ }^{1}$ ); wir wendeu uns nunmehr der Betrachtung der pelagischen Organismen zu.

\section{Die Organismen des Limneticums.}

Über das Plankton des Grundlsees ist meines Wissens bis auf einige Notizen ron Langhans (l. c.) über die Plankton-Cladoceren nichts publiziert worden. Meine eigenen Untersuchungen basieren auf einem Material der Jahre 1911 und 1912, das mir allmonatlich von der k. k. Forstund Domänenverwaltung Grundlsee in Aussee zugeschickt wurde. Die Proben wurden nach meinen Anordnungen stets aus ungefähr derselben Seegegend (zwischen „Krenz" und „Reschenhorn“) entnommen und setzen sich aus je einem Oberflächen- und Tiefenfang zusammen. Sie wurden in Ort und Stelle mit 4 Proz. Formalin konserviert und sogleich zum Versand gebracht. Wie beim Hallstätter See (3) wurden die Untersnchungen mit Rücksicht auf den fischereilichen Zweek ursprünglich nur in qualitativem Sinne ausgeführt und darüber dem k. k. AckerbauMinisterium bereits ein fachliches Gutachten erstattet. Allein das an

I) S. Anm. Seite 442 . 
und für sich sonst schwer zu beschaffende Jahres-Material bot auch in theoretisch-wissenschaftlicher Richtung manch Interessantes dar. So konnten Fragen der temporalen Verteilung (Periodizität), vertikalen Terteilung und Saisonvariation studiert werden, über welche nunmehr in folgendem kurz berichtet werden soll. Als Fangapparate dienten die gleichen, in der Hallstätter Seearbeit bereits beschriebenen Netze und Pumpen. Bei den Untersuchungen wurde anch hier meist nur das Mikroplankton berücksichtigt, während das Namnoplankton mangels geeigneter Filter und Zentrifuge nur insofern festgestellt werden konnte, als es durch das Netz zurückgehalten worden war.

1. Zusammensetzung des Planktons.

Chlorophyceae: Staurastrum gracile Ralf.

Sphaerocystis Sehroeteri Chod.

Oocystis solitaria Witt.

Anabaena flos aquae Breb.

Bothryococcus Brauni Kütz.

Baccilliaraceae: Asterionella gracillima Kütz.

Frngillaria virescens Ralf.

Tabellaria fenestrata Kütz.

Cyclotella compta Kütz.

Mastigophora: Dinobryon divergens Imh.

Peridinium cinctum Ehrbg.

Ceratium hirtundinella O. F. Mäller

Infusoria: Codonella lacustris (Entz.)

Epistylis plicatilis Ehrbg. (passiv auf Cyclops)

Rotatoria: Asplanchna priodonta Gosse

Anuraea cochlearis Gosse

Polyarthra platyptera Ehrog.

Notholca longispina Kellic

Triarthra longiseta Ehrbg.

Conochilus unicornis Rouss.

Crustacea: Daphnia longispina ra. hyalina f. typica (Leydig)

Bosmina coregoni (longispina) Leydig

Scapholebris mucronata var. longicornis (Lutz)

Bythotrepbes longimantus Leydig

Leptodora Kindtii (Focke)

Diaptomus gracilis O. Sars.

Cyclops strenuus Fischer

Nauplien. 
Bemcrkungen zu einzelnen Arten und Gruppen.

Vorlicgendes Verzeichnis enthält 9 Vertreter des Phytoplankton und 19 des Zooplankton, wobei Epistylis plieatilis als passiver Planktont auf Cyclops mit gezählt erscheint. Vergleicht man diese Planktonliste mit jener des Hallstätter Sees, so herrscht große Übereinstimmung. Wir finden in beiden Seen, die ja bekanntlich durch die Traun miteinander in Verbindung stehen, meist die gleichen Arten wieder. Doch ist es aber, wie wir gleich sehen werden, bei einer Art zu einer eigenen Rassenbildung gekommen. Betrachten wir zunächst das Algenplankton, so gilt ron den Chlorophyceen auch hier, daß sie im Grundlsee niemals eine dominierende Rolle eimnehmen. Dagegen sind dic Diatomeen Cyclotella und Asterionella zumal in don Wintermonaten recht häufig; die übrigen finden sich niemals in großen Mengen vor. Melosira fehlt dem Grundlsee ebenfalls vollständig. $Z u$ den häufigsten und stets anzutreffenden Planktonten gehört ferner Ceratium hirundinella. Seine Länge

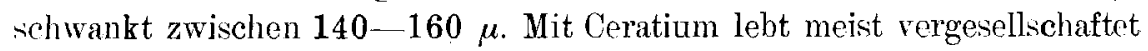
Peridininum cinctum. Dinobryon ist wie im Hallstäter See niemals häufig. Über die angefübrten Rotatorien kann nicht viel gesagt werden. Asplanchna priodonta ist auch hier die häufigste Art, die besonders im Winter ihr maximales Auftreten zeigt. Unter den planktonischen Krustern sind Cladoceren und Copepoden in ihrem quantitativen Auftreten als gleich häufig zu bezeichnen. In welcher zeitlichen Reihenfolge dies geschieht, wird weiter unten ausführlich behandelt werden. Als Daphnia konnte wie im Hallstädter See anch im Grundlsee die Art longispina var. hyalina f. typica festgestellt werden. Thre absolute Gesamtlänge schwankt zwischen 1650 und $2340 \mu$ (s. Tabelle 1). Die Bosmina des Grundlsees gehört ebenfalls zur coregoni-Gruppe und ist wahrscheinlich eine longispina-Form; sie bildet aber, wie dies Rühe bestätigte, hier eine von fler Hallstätter Form leicht zu unterscheidende eigene Rasse. Größe $700-1400 \mu$. Mncro klein, schräg nach unten gerichtet. Erste Antenne sehr lang. wohl am längsten von allen Traunsee Bosminen, stark gebogen, hakenförmig oder S-förmig. Sie nähert sich nach Rühe (9) ählich wie die Gmundner See-Bosmine sehr stark den Formen des baltischen Seengebietes aus der Longicornis-insignis-Gruppe. Bemerkenswert ist ferner, daß die ephippientragenden Weibchen rom Hallstätterund Grundlsee einander recht nahekommen.

Ton Leptodora und Bythotrephes ist an dieser Stelle nichts Besonderes zu bemerken. Dagegen muk das pelagische Vorkommen von 
Maßtabellen von Daphnia und Bosmina.

Tabelle I.

Daphnia hyalina:

\begin{tabular}{|c|c|c|c|c|c|c|c|}
\hline & 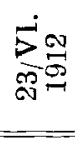 & 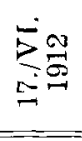 & 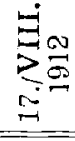 & 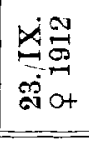 & 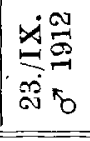 & $\frac{\dot{x}}{\dot{0} \sigma}$ & $\dot{\vec{X}} \overrightarrow{\mathrm{N}}$ \\
\hline$\ldots \ldots$ & 1157 & 1182 & 1216 & 1205 & 1155 & 1183 & $12: 34$ \\
\hline Kopflänge & 158 & 182 & 375 & 205 & 155 & 183 & 234 \\
\hline Augendurchmesser & 52 & 45 & 48 & 66 & 44 & 60 & 54 \\
\hline$a$ & 52 & 64 & 75 & 66 & 51 & 57 & 81 \\
\hline$\beta$ & 42 & 73 & 65 & 98 & 59 & 57 & 81 \\
\hline$\gamma$ & 52 & 64 & 68 & 49 & 44 & 42 & 54 \\
\hline$\delta$ & .126 & 127 & 184 & 157 & 111 & 166 & 214 \\
\hline Scbalenlänge. & 1000 & 1000 & 1000 & 1000 & 1000 & 1000 & 1000 \\
\hline Schalenhöhe . & 484 & 564 & 584 & 595 & 370 & 516 & 533 \\
\hline Spina . & 153 & 254 & 280 & 262 & 296 & 260 & 268 \\
\hline
\end{tabular}

Tabelle II

Bosmina coregoni (nach Rühe):

\begin{tabular}{|c|c|c|c|c|c|c|}
\hline & $\mathrm{T}$ & $H$ & $\operatorname{Pr}$ & $\mathrm{C}+\mathrm{D}$ & 0 & $\mathrm{Mu}$ \\
\hline \multirow{3}{*}{$23 . /$ IV. $19127^{3} / 8^{\circ} \mathrm{C}$} & 994 & 805 & 755 & 910 & 91 & 153 \\
\hline & 1144 & 847 & 825 & 1010 & 100 & 173 \\
\hline & 915 & 770 & 640 & 840 & -77 & 140 \\
\hline \multirow{3}{*}{ 13./VI. $191113,7^{\circ} \mathrm{C}$} & 745 & 818 & 448 & 563 & 114 & 163 \\
\hline & 860 & 857 & 500 & 613 & 140 & 186 \\
\hline & 700 & 790 & 380 & 490 & 83 & 140 \\
\hline \multirow{3}{*}{ 17./VIII. $191120^{\circ} \mathrm{C}$} & 990 & 818 & 648 & 915 & 83 & 198 \\
\hline & 1100 & 844 & 770 & 1000 & 100 & 220 \\
\hline & 900 & 770 & 530 & 800 & 72 & 170 \\
\hline \multirow{3}{*}{$23 . / \mathrm{IX} .1912 \mathrm{~S}^{\mathrm{s}} / 4^{\circ} \mathrm{C}$} & 1036 & 839 & 670 & 966 & 80 & 195 \\
\hline & 1124 & 880 & 800 & 1080 & 85 & 250 \\
\hline & 978 & 810 & 517 & 896 & 70 & 160 \\
\hline \multirow{3}{*}{ 17./XI. $19118^{3} /^{\circ} \mathrm{C}$} & 1204 & 806 & 565 & 842 & 83 & 184 \\
\hline & 1386 & 832 & 608 & 897 & 91 & 216 \\
\hline & 1012 & 768 & 504 & 756 & 80 & 140 \\
\hline \multirow{3}{*}{$\begin{array}{c}\text { Maße von } 3 \text { Ephippium- } \\
\text { weibchen }\end{array}$} & 721 & 762 & 627 & 827 & 107 & 147 \\
\hline & 721 & 762 & 453 & 707 & 93 & 173 \\
\hline & 750 & 743 & 667 & 833 & 90 & 141 \\
\hline
\end{tabular}


Scapholebris mucronata erwähnt werden. Diese Cladocere hat bekanntlich die Eigenschaft, mit dem Rücken nach unten am Oberflächenhäutchen der Wasserfläche hängend dahinzuschwimmen; sie ist der einzige Repräsentant einer "Oberflächenfauna". Rein pelagisch wurde sie bisher aus einigen Schweizer Scen (Vierwaldstätter See, Genfer See, Brienzer See und Walensee) beschrieben; auch Brehm (1) hebt ihr pelagisches Vorkommen im Erlaufsee hervor. Desgleichen Langhans (4) für den St. Wolfgangsee. Derselbe Autor erwähnt schließlich auch ihr Vorkommen im Grundlsee, ohne indessen anzugeben, ob litoral oder limnetisch. Letzteres kann ich num mit Bestimmtheit behaupten, da ich dies Cladocere im Juli und August 1913 ïber größeren Tiefen $(40-50 \mathrm{~m})$ fand. Und zwar tritt die in Grundlsee in der subalpinen Seen eigentümlichen Lokalvariation var. longicornis mit langem Stirmhorn anf.

Über die beiden Plarkton-Copepoden des Grundlsees, Diaptomus gracilis und Cyclops strenuus ist nichts Besonderes zu sagen. Sie sind beide farblos. Cyclops ist oft derart mit Epistylis bewachsen, daß im ganzen Fange nicht ein einziges Exemplar davon frei ist and eine Bestimmung der Art dadurch sehr erschwert wird.

2. Temporale Verbreitung des Planktons.

Ähnlich wie beim Hallstätter See lag es im Rahmen der fischereilichbiologisehen Untersuchungen, ein möglichst genaues Bild über die qualitative /asammensetzung des Grundlsce-Planktons zu erhalten, so daf quantitative Fünge im eigentlichen sinne des Wortes fehlen. Um nun aber auch für das jahreszeitliche Vorkommen der Planktonten dieses Secs einigen Aufschlub zu erhalten, fanden die einzelnen Monatstänge dieselbe Behandlung, wie dies in der Hallstätter-See-Arbeit für diesen See genauer beschrieben ist (3). Leider konnte das Material keinesweg: lückenlos erhalten werden. Im Jänner und Fober 1911 überzog. wie schon früher erwähnt wurde, eine dicke Eisschichte den See, und wurdc leider zu dieser Zeit kein Material gefischt; das gleiche war ini Feber 1912 der Fall. Schließlich ging der Fang rom September 1911 auf der Post in Verlust und konnte trotz Reklamation nicht erniert werden. Trotz dieser Lücken ist es indes doch möglich, sich ein ungefähres Bild über die qualitative und quantitative Zusammensetzung des Jahresplanktons zu machen. Ich lasse im nachfolgendon zunächst eine Tabelle über das Zooplankton folgen (Tabeile III).

Beror ich auf den Entwicklungsgang der cinzelnen Arten eingehe, sei vorerst ein Überblick über die qualitative Zusammensetzung des Planktons in den einzelnen Jahresmonaten gegeben. Das Hallstätter 
Tabelle III.

1911:

\begin{tabular}{|c|c|c|c|c|c|c|c|c|c|c|c|c|}
\hline & 岂 & 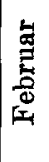 & 亮 & 吾 & 芯 & $\stackrel{\Xi}{\Xi}$ & $\stackrel{\overrightarrow{3}}{\stackrel{\vec{B}}{S}}$ & 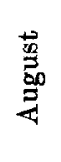 & 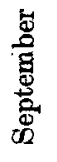 & $\frac{\frac{3}{0}}{\frac{0}{0}}$ & 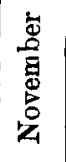 & 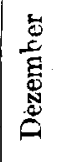 \\
\hline Daphnia byalina & & & & 45 & 13 & 16 & 170 & 110 & & 76 & 25 & 2 \\
\hline Bosminia coregoni . . & 64 & & & 6 & 6 & 33 & 60 & 112 & & 50 & 50 & 24 \\
\hline Bythotrephes longimanus & & & & & & 1 & 2 & 5 & & 2 & 2 & \\
\hline Leptodora hyalina . . & & & & & & & 1 & 3 & & 1 & 1 & \\
\hline Diaptomus gracilis . . & 22 & & & 150 & 500 & 412 & 164 & 10 & & 305 & 125 & 220 \\
\hline Cyclops strenuus . . & 35 & & & 21 & 120 & 92 & 40 & 18 & & 105 & 150 & 200 \\
\hline Asplanchna priodonta & 2 & & & 1 & 3 & 14 & 8 & 8 & & 2 & 45 & 250 \\
\hline Anuraea cochlearis & 3 & & & 3 & 8 & 2 & 2 & 1 & & 1 & 2 & 2 \\
\hline Notholea longispina & 3 & & & 2 & 4 & 5 & 6 & 2 & & 2 & 2 & 4 \\
\hline Ceratium hirundinella & 7 & & & 3 & 20 & 4 & 2 & 2 & & 2 & 5 & 16 \\
\hline
\end{tabular}

1912 :

\begin{tabular}{|c|c|c|c|c|c|c|c|c|c|c|c|c|}
\hline & 离 & 宽 & 䨔 & $\overrightarrow{0}$ & 芯 & $\stackrel{\vec{B}}{\stackrel{B}{g}}$ & 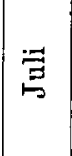 & 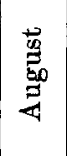 & 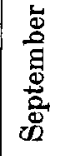 & $\frac{\frac{6}{0}}{\frac{8}{0}}$ & 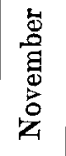 & 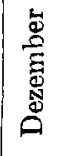 \\
\hline Daphnia hyalina. . . & & & & 16 & 9 & 60 & 80 & 100 & 80 & 40 & 40 & 3 \\
\hline Bosmina coregoni . & 180 & & 20 & 77 & 136 & 320 & 220 & 40 & 30 & 22 & 22 & 13 \\
\hline By thotrephes longimanus & & & & & & & 1 & 2 & $\mathbf{3}$ & 1 & 1 & \\
\hline Leptodora hyalina . & & & & & 1 & 1 & 2 & 5 & 1 & 1 & & \\
\hline Diaptomus gracilis . . & 24 & & 114 & 262 & 3 & 10 & 4 & 40 & 10 & 22 & 6 & 56 \\
\hline Cyclops strenuus . . & 30 & & 8 & 25 & 132 & 63 & 100 & 45 & 150 & 25 & 180 & 284 \\
\hline Asplanchna priodonta. & $\mathbf{3}$ & & 7 & 2 & 10 & 32 & 2 & 1 & 3 & 11 & 25 & 100 \\
\hline Anuraes cochlearis. & 3 & & 2 & 4 & 6 & 4 & 2 & 2 & 2 & 2 & 1 & 1 \\
\hline Notholea longispina & 3 & & 3 & 4 & 3 & 2 & $\mathbf{2 4}$ & 12 & 8 & 1 & 2 & 1 \\
\hline Ceratium hirundinella & 9 & & 1 & 4 & 15 & 6 & 7 & 10 & 4 & 1 & 5 & 12 \\
\hline
\end{tabular}

Plankton kann sowohl als Copepoden- als auch als Cladoceren-Plankton bezeichnet werden. Die Copepoden, insbesondere Diaptomus, dominieren vom Feber bis zum Juni, hierauf folgt im Hochsommer bis in den Spätherbst ein Überwiegen der Cladoceren, und zwar in den Hochsommermonaten Juni-September. Die Wintermonate November und Dezember hat Cyclops sein Maximum. In den Jänner fällt abermals ein 
dominierendes Auftreten von Bosmina (Nebenmaximum). Die Rädertiere bilden eigentlich nur mit Asplanchna priodonta in den Wintermonaten (Dezember) einen wesentlichen Komponenten des Planktons. Über das Phytoplankton fehlen Aufzeichnungen, doch scheint dessen Maximum, was wenigstens die Diatomeen betrifft, in das zeitige Fruhjahr zu fallen.

Nach diesen kurzen Erörterungen setzt sich demmach das Plankton in den einzelnen Monaten folgendermaßen zusammen:

Tabelle IV.

\begin{tabular}{|c|c|c|c|}
\hline & 1910 & 1911 & 1912 \\
\hline Januar & - & $\begin{array}{l}\text { Bosmina und } \\
\text { Cyclops Pl. }\end{array}$ & Bosmina Pl. \\
\hline Februar & - & - & - \\
\hline März & - & - & Diaptomus PI. \\
\hline April & - & Diaptomus $\mathrm{Pl}$. & Diaptomus $\mathrm{Pl}$. \\
\hline Mai & Diaptomus $\mathrm{Pl}$. & Diaptomus Pl. & $\begin{array}{l}\text { Cyclops Pl. } \\
\text { (Bosmina) }\end{array}$ \\
\hline Juni & $\begin{array}{l}\text { Diaptomus und } \\
\text { Cyclops PI. }\end{array}$ & Diaptomus Pl. & Bosmina Pl. \\
\hline Juli & $\begin{array}{l}\text { Daphnia und } \\
\text { Bosmina Pl. }\end{array}$ & $\begin{array}{l}\text { Daphnia und } \\
\text { Bosmina Pl. }\end{array}$ & Bosmina Pl. \\
\hline August & Daphnia Pl. & $\begin{array}{c}\text { Daphnia und } \\
\text { Bosmina Pl. }\end{array}$ & Daphnia PI. \\
\hline September & Daphnia Pl. & 一 & $\begin{array}{l}\text { Cyclops und } \\
\text { Daphnia Pl. }\end{array}$ \\
\hline Oktober & $\begin{array}{l}\text { Diaptomus und } \\
\text { Cyclops Pl. }\end{array}$ & $\begin{array}{l}\text { Diaptomus und } \\
\text { Cyclops Pl. } \\
\text { (Daphnia) }\end{array}$ & $\begin{array}{l}\text { Cyclops und } \\
\text { Daphnia PI. }\end{array}$ \\
\hline November & $\begin{array}{l}\text { Diaptomus und } \\
\text { Cyclops Pl. }\end{array}$ & $\begin{array}{l}\text { Cyclops und } \\
\text { Diaptomis Pl. }\end{array}$ & Cyclops Pl. \\
\hline Dezember & $\begin{array}{l}\text { Diaptomus und } \\
\text { Cyclops Pl. }\end{array}$ & $\begin{array}{l}\text { Diaptomus und } \\
\text { Cyclops Pl. } \\
\text { (Asplanchna) }\end{array}$ & $\begin{array}{l}\text { Cyclops Pl. } \\
\text { (Asplanchna) }\end{array}$ \\
\hline
\end{tabular}

Vergleicht man das Plankton des Hallstätter und Grundlsees in bezug auf seine qualitative Jahreszusammensetzung, so ergeben sich bedeutende Unterschiede. Das Hallstätter Seeplankton ist fast durchweg ein typisches Copepodenplankton, in dem die Cladoceren ganz zurücktreten, das Grundlseeplankton dagegen in den Sommermonaten ein typisches Cladocerenplankton. Diese Eigenschaft ist in fischereilich-biologischer Beziehung für den Grundlsee von größter Bedeutung. 
Entwicklungsgang einzelner Arten und Gruppen.

Die Grünalgen scheinen im Grundlsee infolge der kalten Wassertemperatur nur im geringen Maße zur Entwicklung zu kommen. Wenigstens konnte ich während meines wiederholten Besuches des Sees im Hochsommer ein starkes Überhandnehmen der Chlorophyceen, die Bildung einer Wasserblüte, niemals wahrnehmen. Die Diatomeen haben ihr Maximum, wie trotz Fehlens geeigneter Daten mit großer Sicherheit angenommen werden kann, im zeitigen Frühjahre. Die gleiche Erscheinung konnte ja bereits für den Hallstätter See konstatiert werden.

Von Flagellaten sind Dinobry on divergens, Peredinium cinctum und Ceratium hirundinella Plank tonkomponenten. Die beiden ersteren treten durch ihr sporadisches Auftreten ganz in den Hintergrund, während Ceratium hirundinella stets im Plankton anzutreffen ist. Die Peridinee ist also perennierend, wobei das Maximum des Auftretens in den Mai fällt. Im Hallstätter Sce konnte dasselbe dagegen im Herbst festgestellt werden. Die Form tritt stets vierhörnig auf, die Größe schwankt zwischen 140 bis $160 \mu$.

Von Rotatorien des Grundlsees ist Asplanchna priodonta die größte und häufigste Form. Die Art ist für den See perennierend. Wie im Hallstätter See kann man auch für den Grundlsee zwei Maxima unterscheiden, wovon das eine ein Frühjahrs-Nebenmaximum (Juni), das andere ein typisches Winter-Hauptmaximum (Dezember) ist. Damit erfährt das von verschiedenen Autoren für eine Reihe von Alpenseen beobachtete maximale Auftreten von Asplanchna im Winter eine neuerliche Bestätigung. Im Dezemberfang (1911) konnten ferner Männchen vorgefunden werden. Anuraea cochlearis tritt als irregularis-macracantha-Form auf und erreicht eine durchsebnittliche Panzerlänge ron $140-160 \mu$ (Breite $60 \mu$, Hinterdorn $50 \mu$ ). Die Rotifere ist perennierend und besitzt maximales Auftreten im Monat Mai. Dadurch unterscheidet sie sich wesentlich von jener des Hallstätter Sees, deren Maximum in den September fällt. Sie erinnert vielmehr an die Form der dänischen und finnischen Seen, deren Maximum ebenfalls im Mai und Juni festgelegt wurde. Von Mai bis Juli sind eitragende Individuen sehr häufig. Notholca longispina ist im Grundlsee das ganze Jahr über anzutreffen, ist also perennierend. Ähnlich wie im Hallstätter See ist diese Rotifere eine typische Sommerform, deren maximales Auftreten in den Hochsommer (Juli) fällt. Ein zweites Nebenmaximum, wie dies Burckhardt im Vierwaldstätter See, Fuhrmann im Neuenburger See, Heuscher 
im Sempacher See, Brehm für den Achensee nachgewiesen hatten, konnte im Grundlsee nicht konstatiert werden. Eitragende Tiere wurden in den Monaten Mai-August recht häufig angetroffen. Über Polyarthra platyptera und Triarthra longiseta fehlen jahreszeitliche Aufzeichnungen.

Daphnia hyalina. Über den Generationszyklus dieser Cladocere liegen bekanntlicherweise verschiedene Beobachtungen vor. In einigen Schweizer Seen hat sie die Eigenschaft, Ephippien zu bilden, aufgegeben (Vierwaldstätter See). Im Bodensee kommt es dagegen zur Ephippienbildung. Ebenso im Achensee, wo im Herbst Männchen auftreten und die Art von Ende Dezember bis Mai aus dem Plankton verschwindet. In ähnlicher Weise konnte Brehm (1) im Erlaufsee Ephippienbildung, aber keine Männchen nachweisen. Im Hallstätter See kommt nach meinen Unterstuchungen (3) Daphnia hyalina perennierend vor, wobei Ephippienbildung und Männchen in einem Jahre (1911) festgestellt wurden, im anderen (1912) dagegen nicht. Das maximale Auftreten fällt in diesem See in die Monate September-Oktober. Ganz anders verhält sich die Art im Grundlsee. Langhans (4) erwähnt nur kurz, daß er sie im Material vom Jahre 1886 im Monat Oktober „in Sexualperiode" angetroffen hat. Auf Grund der Untersuchungen der Planktonfänge 1910-1912 nimmt der Entwicklungszyklus von Daphnia hyalina im Grundlsee fast den gleichen Verlauf wie ihn Brehm (2) für den Achensee angibt. So ist vor allem die Form keineswegs azyklisch und perennierend, sondern monozyklisch und verschwindet Ende Dezember bis Mitte April aus dem Plankton vollständig. Im April treten die ersten, den Wintereiern entschlüpften juvenilen Tiere auf und werden bereits im Mai reif. Es folgt bis zum September eine Periode starker parthenogenetischer Entwicklung, welche im Juli bzw. August ihr Maximum erreicht. Im September erscheinen die ersten Männchen, werden an Zahl häufiger und erreichen November ihre Höchstzahl. Mitte September fällt bereits der Beginn der Ephippienbildung, die mit Dezember abgeschlossen wird. In diesem Monate verschwinden die letzten Exemplare vollständig, man findet nur noch leere Schalen.

Übersichtlich dargestellt stellt sich die Periodizität von Daphnia hyalina folgendermaßen dar:

Eirstes Auftreten:

Stärkere Zunahme unter lebhafter Sabitanei-

Bildung, Maximum:

Langsame Abnahme:

Erste Hälfte April

Anfang Mai-Juli, August

September-November 
Frstes Auftreten der Männchen:

Dauereierbildung:

Letztes Auftreten:

Dauerstadium:
Anfang September:

Mitte September-Dezember

Ende Dezember

Anfang Jänner-April.

Bosmina coregoni. Die Ansicht von der ausschließlich parthenogenetischen Fortpflanzung alpiner Bosminen hat zuerst durch die Beobachtung von Langhans (4) sowie durch Rühe (9) und meine Untersuchungen (3) der Salzkammergutbosminen vollständig an Gültigkeit verIoren. So konnte ich schon im Hallstätter See feststellen, daß Bosmina coregoni im September, ja sogar schon im Juli zur Ephippienbildung. schreitet, ohne daß irgendwann Männchen auftraten. Im Grundlsee ist clie Form ebenfalls perennierend. Im Verlaufe eines Jahres treten zwei Maxima auf, ein Nebenmaximum im Jänner, ein Hauptmaximum Ende Juni bzw. Mitte August. In den Monaten März bis September sind stets ausgewachsene Individuen mit vielen Subitaneiern und Embryonen im Brutraum anzutreffen. Im Herbst stzt eine ausgesprochene Geschlechtsperiode ein, die 1911 ausnahmsweise schon im August mit der Bildung von Ephippien beginnt, ohne daß vorher Männchen aufgefunden worden wären. Die Dauerei-Bildung erreicht im Oktober ilhren Höhepunkt, ohne daß aber die Bildung von Subitaneiern gan\% ausgesetzt hätte. Es konnten noch im Dezember 1912 Weibchen mit solchen angetroffen werden. Es geht demnach hier parthenogenetische und geschlechtliche Fortpflanzung parallel nebeneinander her. Das erklärt auch die große Schwierigkeit in der Erklärung einer Cyclomorphose der Grundlsee-Bosmina, indem man es wahrscheinlich mit verschiedenen Stämmen zu tun hat. Auffallend ist die geringe Zahl von Männchen, deren erstes Auftreten im September nachgewiesen werden konnte. Zu beachten ist ferner, wie dies bereits $R \ddot{u} h \mathrm{e}(9)$ hervorhebt, die größere Anzahl von Geschlechtstieren Mitte September 1912 bei einer Wassertemperatur von $6,2^{\circ} \mathrm{C}$ gegenüber derselben Zeit des Vorjahres bei einer Wassertemperatur von $8,7^{\circ} \mathrm{C}$. Nach obigen Ausführungen läßt sich der Entwicklungszyklus für Bosmina des Grundlsees folgendermaßen ungefähr skizzieren:

Frühjahrsminimum:

Sommer- (Haupt-) Maximum:

Abnahme:

Winter- (Neben-) Maximum:

Erstes Auftreten der Männehen: September

Dauereibildung:
Februar-April

Juni-August

August-Dezember

Jänner

(August) September-Dezember. 
Bythotrephes longimanus. Über diese große Cladocere sind wir aus Arbeiten Burckhardts, Lilljeborgs u. a. gut unterrichtet. Aus allen geht die Monozyklie dieses Planktonten deutlich hervor. Für den Hallstättersee konnte ich das Fehlen von Bythotrephes im winterlichen Plankton von November bis Mai feststellen. Das Maximum fällt hier in den August, während Oktober die ersten Männchen auftreten. Im Grundlsee finden sich ganz ähnliche Verhältnisse. Hier tritt Bythotrephes im Juni-Plankton zum ersten Male auf und erreicht im August bzw. September das Maximum. Im Oktober bzw. November beginnt mit Auftreten von Männchen die Geschlechtsperiode, welche mit der Abrage von Dauereiern beendet wird. Von Dezember bis Ende Mai rerschwindet Bythotrephes vollständig ans dem Sceplankton.

Leptodora hyalina. Burckhardt komnte diese hyaline Cladocere im Vierwaldstätter See von Juni bis Ende November konstatieren, wobei das Maximum des Auftretens in den August fällt. Im Hallstätter see fand ich ganz ähnliche Verhältnisse vor: Erstes Auftreten im Juni, Maximum im August, Auftreten von Männchen und Ephippienwcibchen im Oktober. Ruhestadium November bis Juni. Für den Grundlsee konnte ich die gleiche Monozyklie feststellen. Das erste Auftreten fällt hier allerdings sehon in den Monat Mai (1912); das Maximum jedoch gleichfalls in -den August. Im Oktober erschcinen Männehen, worauf bald Ephippienablage erfolgt. Das Dauerstadium währt hier von Ende Norember bis Anfang Mai.

Diaptomus gracilis. Dieser Centropagide besitzt in den Alpenseen in der Regel zwei Maxima, wovon eines in das Frühjahr (Hauptmaximum) und eines in den Herbst oder Winter (Nebenmaximum) fällt. Solche Verhältnisse komnten sowohl für den Vierwaldstätter See als auch für den Erlauf- und Hallstätter See festgestellt werden. In letzterem fällt. das Frähjahrsmaximum in den Juni, das Herbstmaximum in den September-Oktober. In ähnlicher Weise gestaltet sich der Entwicklungszyklus im Grundlsee. Auch hier perenniert der Copepode, erlangt aber im Gegensatz zum Hallstätter See nur im Frihjahre eine dominierende Stellung in der Zusammensetzung des Planktons. Es sind die Monate April oder Mai, in die das Hauptmaximum fällt. Das Herbst- oder Nebenmaximum konnte ich in einem Falle (1911) im Oktober feststellen, im Jahre 1912 scheint es sich aber gegen den Winter 1913 verschoben zu haben. Männehen wurden besonders im Frühjahr und Herbst recht häufig konstatiert, während juvenile Tiere im Juli sehr häufig waren. 
Die Weibchen tragen zur Zeit des Frühjahrsmaximums in der Regel Eierpackete mit 6-14 Eiern.

Cyclops strenuus. In den Seen der Ebene besitzt dieser pelagische Cyclopide gewöhnlich zwei Maxima, von denen eines in das Frühjahr oder den Sommer, das andere vorwiegend in den Winter fält. So konnte ich im Hallstätter See das erste Maximum im Mai, das zweite in Oktober oder Anfang Nobember nachweisen. Im Grundlsee tritt nun das Frühjahrsmaximum ebenfalls im Mai auf, während das zweite Maximum zeitlich eine Verschiebung gegen den Winter in den Monat Dezember genommen hat. In dieser Beziehung gleicht der Grundlsee den Scen des Tieflandes, in denen stets ein Winte.maximum von C. strenuus konstatiert wurde. Was die Verteilung der beiden Geschlechter dieses Copepoden im Grundlsee betrifft, so können die Männchen in den Frühjahrsund Herbstmonaten sehr zahlreich angetroffen werden, fehlen aber Juni und August fast vollständig. $\mathrm{Zu}$ dieser Zeit sind dagegen juvenile Tiere sehr" häufig. Die Hauptmenge der eitragenden Weibchen findet man in den den beiden Maxima vorangehenden Monaten. Die beiden Eiersäcke enthalten 6-10 Eier.

\section{Vertikale Verbreitung des Planktons.}

Über diese in den meisten Alpenseen verbreitete Erscheinung habe ich in meiner Hallstätter-See-Arbeit ausführlich berichtet, so daß es sich hier erübrigt, nochmals darauf zurückzukommen. Die von mir am 28. August 1912 im Grundlsee ansgeführten Stufenfänge gestatten einen ungefähren Einblick in die vertikale Verteilung des Planktons dieses Sees und lassen einen Vergleich mit jener des Hallstätter Sees zu. In der folgenden Tabelle sind für das Auftreten der einzelnen Planktonten in den verschiedenen Tiefen abermals Abundanzzeichen eingesetzt.

Die vertikale Schichtung des Grundlsee-Planktons läßt sich nach obiger Tabelle für den 28. August 1912 folgendermaßen zusammenfassen:

Oberfläche bis $3 \mathrm{~m}$ : Ceratium und Dinobryon dominierend. Daphnia, Polyarthra und Notholca häufig,

schichte $3-5 \mathrm{~m}$. Daphnia dominierend, Bosmina und die genannten Rotatorien sehr häufig, Ceratium massenhafr.

Sichichte 5-10 m: Daphnia und Bosmina sehr häufig, desgleichen die bekannten Rotatorien. Auch Ceratium und Dinobryon noch häufig anzutreffen.

Schichte $10-20 \mathrm{~m}$ : Copepodenzunahme, Cladoceren bis auf Bythotrephes selten, Ceratium häufig. 
Schichte 20-30 m: Copepoden vorherrsehend, Cladoceren selten, Rädertiere mit Ausnahme von Asplanchna selten.

Schichte $30-40 \mathrm{~m}$ : Copepoden dominierend, Bythotrephes häufig. Rädertiere selten.

Tabelle $\mathrm{V}$.

\begin{tabular}{|c|c|c|c|c|c|c|c|}
\hline $28 . / 1$ & 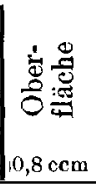 & $\begin{array}{c}\mathbb{G} \\
\sim \\
1 \\
r \\
0,5 \mathrm{ccm} \\
\end{array}$ & $\begin{array}{c}9 \\
10 \\
1 \\
0 \\
3,0 \mathrm{~cm}\end{array}$ & $\begin{array}{c}8 \\
0 \\
10 \\
2.5 \mathrm{~cm}\end{array}$ & $\begin{array}{c}\mathbb{g} \\
\stackrel{0}{0} \\
1 \\
0 \\
-1 \\
2 \mathrm{ccm} \\
\end{array}$ & $\begin{array}{c}a \\
8 \\
1 \\
8 \\
1,4 \mathrm{ccm}\end{array}$ & $\begin{array}{c}E \\
\stackrel{\Xi}{\sharp} \\
\stackrel{1}{1} \\
1,2 \mathrm{~cm}\end{array}$ \\
\hline . . . . & t & O & $\bullet$ & * & + & + & - \\
\hline Bosmina coregoni. . . . . & + & + & $*$ & * & + & + & - \\
\hline eptodora hyalina . . . . & & & - & + & + & * & \\
\hline Bythotrephes longimanus . . . & & - & - & + & + & 米 & 米 \\
\hline Oiaptomus gracilis . . . . & - & - & - & 米 & O & $\bullet$ & O \\
\hline yclops strenuus & - & - & - & - & 米 & * & 米 \\
\hline Nauplius & - & - & - & - & * & * & * \\
\hline Asplanchna priodonta. & & & & & + & + & + \\
\hline An & - & - & - & - & + & + & + \\
\hline & * & *⿻丷木大 & 米 & * & + & + & - \\
\hline tera . . . & 米 & * & 米 & $*$ & + & t & t \\
\hline a longiseta . . . . & - & - & - & - & + & + & + \\
\hline Ceratiun hirundinella. . & 0 & $\bullet$ & $\bullet$ & 0 & * & + & + \\
\hline Cyclotella compta. . . . . & + & + & + & - & - & - & - \\
\hline Staurastrum gracile. . . . & - & - & - & - & - & 一 & - \\
\hline Dinobryon divergens. . . & $\bullet$ & $\bullet$ & 0 & 0 & * & + & + \\
\hline Temperatur . . & $16^{\circ} \mathrm{C}$ & $16^{\circ} \mathrm{C}$ & $14,9^{\circ} \mathrm{C}$ & $11^{\circ} \mathrm{C}$ & $6,5^{\circ} \mathrm{C}$ & $5,9^{\circ} \mathrm{C}$ & $5.2^{\circ}$ \\
\hline
\end{tabular}

- dominierend, o sehr häufig, *⿻丷木 häufig, + selten, - sehr selten.

Wie im Hallstätter See besteht auch im Grundlsee das Plankton in don Oberflächen-Schichten hauptsächlich aus Flagellaten; Notholoa longispina und Polyarthra platyptera sind ebenfalls recht häufig. Twischen 3-10 $\mathrm{m}$ findet die größte Anhäufung der beiden Cladoceren Daphnia hyalina und Bosmina coregoni statt und zwischen $10-40 \mathrm{~m}$ dominieren die Copepoden Diaptomus gracilis und Cyclops strenuus. Von Bythotrephes sei erwähnt, daß derselbe sich im Grundlsec mehr als 'liefenbewohner charakterisiert. Die übrigen Rotutorien sind (Anuraea, Asplanchna, Triarthra) mehr oder weniger selten und lassen keine besonders deutliche Scbichtung erkennen. Eine Ausnahme macht Triarthra longiseta, 
die sich als Tiefenform charakterisiert. Ceratium hirundinella steigt ebenfalls ziemlich tief hinunter.

Die maximale Anhäufung des Grundlsee-Planktons während des Hochsommers findet sich in der Schicht $3-5 \mathrm{~m}$; aber auch zwischen $5-10 \mathrm{mi}$ sind quantitative Fänge noch ausgiebig. Von da ab nimmt die Planktonmenge rasch ab. Natürlich spielt auch hier die vertikale Wanderung des Planktons eine gewisse Rolle, indem zu verschiedener Jahres- und Tageszeit die maximale Anhäufung von der Lichtintensität beeinflußt wird: Das Phänomen der Vertikalwanderung des Planktons hat ähnlich wie im Hallstätter See auch im Grundlsee für dessen Fischerei eine nicht unwesentliche Bedeutung, von der im fischerei-biologischen Teil dieser Abhandlung noch die Rede sein wird.

Zum Schlusse noch einige Worte ïber die relative Menge des GrundlseePlanktons: Die Berechnung erfolgte auf Grund derselben Pumpmethode, wie sie beim Hallstätter See angewandt worden war, so daß es möglich ist, auf diese Weise einen Vergleichswert zu erhalten. Am Abend (9 Uhr) des 7. Septembers 1914 wurden erbeutet: In $20 \mathrm{~m}$ Tiefe $0,4 \mathrm{~cm}^{3}$, $1 \mathrm{~m} 0,2 \mathrm{~cm}^{3}, 2 \mathrm{~m} 0,2 \mathrm{~cm}^{3}$ Plankton pro 50 Liter Seewasser, oder auf den $\mathrm{m}^{3}$ Wassermenge berechnet $8 \mathrm{~cm}^{3}$ bzw. $4 \mathrm{~cm}^{3}$ Plankton. Mit dem Oberflächenfang des Hallstätter Planktons verglichen, dessen Menge sich mit $7 \mathrm{~cm}^{3}$ berechnet, stellt sich jener aus dem Grundlsee als der ergiebigere dar. Es unterliegt keinem Zweifel, daß der Grundlsee als der bedeutend planktonreichere See anzusprechen ist. Auch diese Tatsache gowinnt in fischereilicher Beziehung erhöhte Bedeutung.

\section{Die horizontale Verteilung des Planktons.}

Über diese ist im Grundlsee nichts Neues zu bemerken, es gilt hier wie im Hallstätter See das Gesetz der gleichförmigen Verteilung des Planktons, soweit die eulimnetische Region in Betracht kommt. In ähnlicher Weise wie im Hallstätter. See tritt ferner eine Veränderung in der Zusammensetzung des Planktons bei Annäherung gegen das Ufer auf. Die Erscheinung der Uferflucht wird durch das Verschwinden von Brthotrephes longimanus und Daphnia hyalina zum Ausdrucke gebracht. Umgekehrt findet in etwa $100 \mathrm{~m}$ Uferentfernung in starkem Maße der Übertritt vadaler Organismen in das limnetische Gebiet statt. Auch hier ist in erster Linie Chydorus sphaericus zII nennen. Doch auch Sida crystallina, Acroperus harpae, Simocephalus vetulus und Peracantha truncata sind in dieser Grenzzone häufig vertreten. 
5. Die Variationen des Planktons.

In der Hallstätter See-Arbeit wurde bereits ausgeführt, daß mit Rücksicht auf die Kälte und 'Tiefe der Ostalpenseen die Variạtionserscheinungen der einzelnen Planktonten goringe sind und es oft sehr schwierig ist, zwischen Variationen, die durch verschiedene Altersstadien und solchen, die jahreszeitlich bedingt sind, zu unterscheiden. War es schon im Hallstätter See schwierig, bei den einzelnen Planktonformen diese beiden Variationsarten voneinander zu trennen, so ist dies bei denen des Grundlsees erst recht der Fall. So konnte ich bei Ceratium hirundinella zwischen Sommer- und Wintertieren nur eine ganz geringe GröBendifferenz von kaum $20 \mu$ feststellen, so daß ich es nicht wage, hier von einer Variationserscheinung überhaupt zu sprechen. Von den Rotatorien Asplanchna priodonta und Anuraea cochlearis gilt das gleiche. Mit einigermaßen Sicherheit kann nur bei den beiden Cladoceren Daphnia hyalina und Bosmina coregoni von einer Variation gesprochen werden, und zwar bei ersterer mehr ron einer Altersvariation, bei letzterer von einer jahreszeitlichen.

Daphnia hyalina: Diese Cladocere besitat gleichwie in Hallstätter See keine Helmbildung, vielmehr nur eine geringe Cristabildung. Wie die Tabelle (III.), in welcher nach der Meßmethode Burckhardts die Durchschnittsmaße von Daphnien aus Fängen gerader Monate eines Jahres (1912) enthalten sind, zeigt, wächst der Wert a (Projektion der Distanz Scheitel-Augenzentrum) von $52 \mu$ auf $75 \mu$ im Monat August. Die Spina erreicht in gleichem Monate den Höchstwert von $280 \mu$. Die absolute Gesamtlänge bewegt sich zwischen $1650 \mu$ bis $2280 \mu$ bei Weibchen, während die Männchen infolge längerer Spina $2340 \mu$ erreichen (s. 'Textfigur 5).

Bosmina coregoni. Bezüglich der Cyclomorphose dieser Cladocere liegen aus neuester Zeit ausfïhrliche Untersuchungen von Rühe (9) vor, welche ich hier zugrunde lege (s. Tabelle IV). Rühe unterscheidet in dem ihm von mil zur Verfügung gestellten Material vier nicht nur durch Messung und-Aufstellung von Durchschnittswerten feststellbare. sondern auf den ersten Blick deutlich erkennbare jahreszeitliche Formen. Zuerst Tiere rom Monat April, die etwa $1000 \mu$ grob sind und ausgewachsene. Exemplare vorstellen. Von allén Saisonformen besitzen sie den kürzesten Mucro und große Antennen, deren Spitze infolge starker hakenartiger Krämmung zur Mucrospitze, mitunter sogar zum Bauch dis Tieres hinweist. Das Auge ist mittelgroB. Die Tiere tragen meist 2 Eier. Im Juni tritt eine gänzlich abweichende Form auf, die blob 
$750 \mu$ mißt und in ihrem Habitus noch ebenfalls als ausgewachsene Form anzusprechen ist. Sie trägt im Brutraum 3-5 Eier und besitzt einen kurzen Mucro, unterscheidet sich aber vor allem durch ihre kurzen, nur wenig gekrümmten langen Antennen von den Apriltieren. Im August folgt dieser Form eine weit größere $(1000-1200 \mu)$ mit langen Tastantennen, die nicht hakig nach hinten gerichtet, sondern nur wenig .gleichmäßig gekrümmt sind, mitunter auch fast gerade gestreckt oder
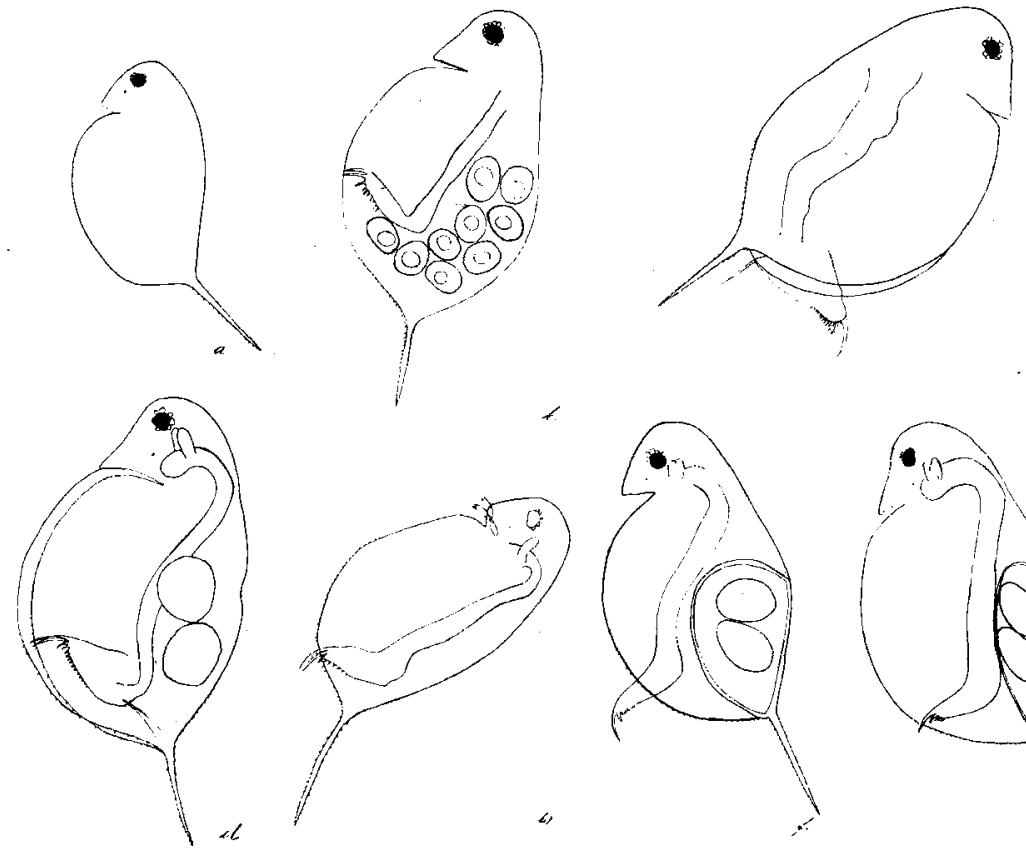

Fig. 5. Daphnia hyalina des Grundlsees und ihre Temporalformen (Vergr.).

a) 우 vom 23./4. 1912 (T. $7,5^{\circ} \mathrm{C}$ )

d) q rom 23./9. $1912\left(8,7^{\circ} \mathrm{C}\right)$

b) 우 vom 17./6. $1912\left(10^{\circ} \mathrm{C}\right)$

e) $0^{7}$ vom $23 . / 9 . \quad 1912\left(8,7^{\circ} \mathrm{C}\right)$

c) 우 rom $17 . / 8.1912\left(15^{\circ} \mathrm{C}\right)$

f) $\mathrm{E} q$ rom $20 . / 10.1912\left(8,7^{\circ} \mathrm{C}\right)$

g) Eq vom 17./12. $1912\left(4,3^{\circ} \mathrm{C}\right)$

S-förmig gestaltet mit nach vorn gebogener Spitze. Ihr Mucro ist beträchtlich größer wie bei den beiden vorhergehenden Formen. Das Auge ist klein. Diese Hochsommerform steht der Aprilform weit näher als der Juniform. Im September treten schließlich Ephippialweibchen auf, die einen vierten Formzustand repräsentieren. Sie sind viel kleiner und flacher als alle anderen Formen und besitzen einen kiurzen, nach hinten gerichteten Mucro. Nun fällt, wie Rühe sagt, am meisten auf, daß die Formen von April und August so weitgehend übereinstimmen, trotzdem 
sie unter extrem rerschiedenen Temperaturverhältnissen (April $71 / 2^{\circ} \mathrm{C}$, August $20^{\circ} \mathrm{C}$ ) leben. Dagegen unterscheiden sich die Tiere rom Juni, trotzdem sie bei einer mittleren l'emperatur leben $\left(13,7^{\circ} \mathrm{C}\right)$, sehr stark von den beiden ersteren Formen. Sie tehen andererseits den im Herbst auftretenden Ephippialweibchen auffallend nahe. Rülie wirft die Frage auf, ob diese Unterbrechung des ganzen Formenzyklus durch die Juniformen auf dem Auftreten einer neuen jungen Generation beruht oder ob in dieser Ubereinstimmung ein Hinweis anf eine ansgefallene Frühjahrsgeschlechtsperiode gesehen werden kann und spricht sich mit aller Reserve für letztere ans. Nach seinen Untersuchungen ist es sehr schwierig, die Richtung der Variation in eine eindeutige Beziehung zum

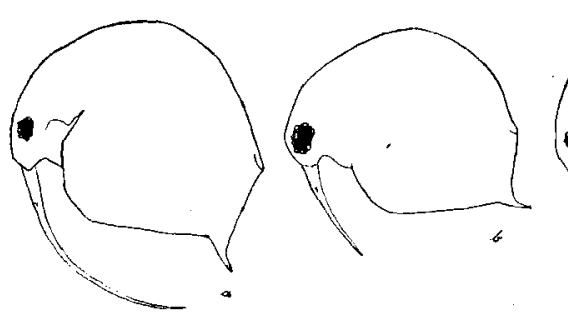

Fig. 6. Boswina coregoni vom Grundlsee und ihre Temporalformen.

a) vom $23 . / 4$. 1912 bei $7 \frac{1}{{ }^{\circ} \mathrm{C}}$ o mit 2 Eiern

b) vom 13./6. 1911 bei $13,7^{\circ} \mathrm{C}$ 우 mit 5 Eiern

c) vom 17./8. 1911 bei $20^{\circ} \mathrm{C} q$ mit 3 Eiern

d) vom $17 . / 11.1912$ bei $64^{1} /{ }^{\circ} \mathrm{C} \mathrm{E}$ q
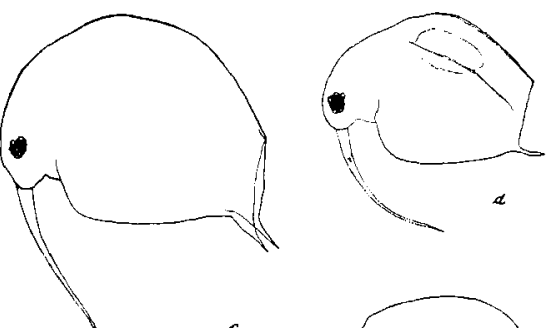

Gang der Temperatur zu setzen. Nur der Wert für den Mucro scheint mit steigender Temperatur gleichmäßig zuzunehmen und mit fallendor zum Herbst hin wieder abzunelimen (s. Textfigur 6).

Bei Copepoden konnte eine Varationserscheinung, wie sie für den Cyclops strenuus des Hallstätter Sees konstatiert worden ist, nicht festgestellt werden.

\section{Fischerei-Biologie des Grundlsees.}

Der Grundlsee ist ein ausgesprochener Saiblings-See; sein wirtschaftlich wichtigster Hauptfisch ist der Seesaibling (S. salvelinus L.). Alle anderen im See lebenden Fische gehören den Nebenfischen an. Es sind dies, wic ans dem auf Seite 452 gegebenen Verzeichnisse hervorgeht, die Bachforelle (Trutta fario L.), die Seeforelle (Irutta lacustris L.), das Aitel (Squalius cephalus Ag:), die Mairenke (Alburnus mento Ag.), die Laube (Alburmms lucidus Heck), dic Pfrille (Phoxinus laevis Ag.), die 
Rutte (Lota rulgaris Cuv.) und der Koppen (Cottus gobio L.). Im ganzen wird der Grundlsee von 9 Fischarten berölkert. Nehmen wir auch in diesem See eine Differenzierung in Raub- und Friedfische vor, so stehen 5 Raubfischen (Bachforelle, Seeforelle, Aitel, Rutte, Koppen) 4 Friedfische (Saibling, Mairenke, Laube und Pfrille) gegenüber. Weniger scharf läßt sich eine ökologische Einteilung durchführen. Ausgesprochene Uferfische des Sees sind Bachforelle, Aitel, Pfrille und Koppen; zu den pelagischen Fischen zählt der Saibling und die Seeforelle, während große Saiblinge und Rutten den ejgentlichen. Tiefseefischen zugerechnet werden. Eine besondere Stellung, nämlich bald Uferfisch, bald rein pelagischer Bewohner, nimmt Laube und Mairenke ein. Bei einer fischereilichen Bewertung des Grundlsees sind nunmehr in ähnlicher Weise wie beim Hallstätter See folgende drei Fragen zu beantworten: Welche Fische verdienen bei voller Berücksichtigung der Flora und Fauna des Grundlsees und der Nahrung der Fische einer besonderen Pflege? Kann nur ein Hauptfisch gezüchtet werden oder können nebeneinander mehrere Arten bestehen, ohne daß gegenseitig eine Schädigung erwächst, die schließlich eine Degeneration zur Folge hat? Fmpfiehlt sich zwecks rationeller Ausnutzung der im See konstatierten Naturnahrung die Einbürgering fremder Fischarten, und welche kommen in obigem besonderen Falle in Betracht?

Zur Beantwortung dieser Fragen ging ich in derselben Weise wie beim Hallstätter See vor, d. h. es war nötig, durch Untersuchung des Darm- und Mageninhaltes der einzelnen Fischarten die aufgenommene Nahrung festzustellen, um erst dann einen Rückschluß zu machen. Den Bemühungen der Forst- und Domänenverwaltung Grundlsee in Aussee verdanke ich die Zusendung eines reichen Materials der wichtigsten Seefische (Saibling, Bachforelle, Seeforelle, Aitel, Mairenke, Laube und Rutte); da dasselbe aus den verschiedensten Monaten des Jahres stammte, war es möglich, einen Überblick über die Haupt- und Gelegenheitsnahrung der einzelnen Fische zu gewinnen. Im folgenden sei aus meinen Protokollen das Wichtigste wiedergegeben und gleichzeitig bei den einzelnen Fischspezies jene biologischen Daten angeführt, welche für den See von Bedentung sind.

1. Der Seesaibling (Salmo salvelinus L.), welcher infolge seiner nordischen Abstammung einen ausgesprochenen Kaltwassercharakter trägt, ist wie in den meisten Seen, die er bewohnt, auch im Grundlsee vorwicgend ein Bewohner der tieferen Wasserschichten $(6-20 \mathrm{~m})$ und bält sich nur zeitweise bei seinen Wanderungen, die er in Schwärmen 
vollführt, in höheren Wasserschichten (über $15-20 \mathrm{~m}$ ) auf. Der Grundlsee-Saibling besitzt vorzügliche Rasseeigenschaften: er ist ein hochrückig $(6-8 \mathrm{~cm})$ gebauter Fisch mit raschem Wachstum. Bei zwei von mir nach der Schuppen- und Otolithenmethode untersuchten ausgewachsenen Exemplaren waren die körperlichen Maß- und Gewichtsverhältnisse folgende:

a) 4 jähriger Fisch ơ Länge: $34,5 \mathrm{~cm}$, Umfang: $15 \mathrm{~cm}$, Gewicht. $320 \mathrm{~g}$ b) 5 jähriger Fisch $\sigma^{7}$ Länge: $39 \mathrm{~cm}$, Umfang: $17 \mathrm{~cm}$, Gewicht: $490 \mathrm{~g}$.

Nach Angaben des staatlichen Fischerei-Inspektors, Herrn E. Doljan, betrug das durchschnittliche Fanggewicht der Grundlsee-Saiblinge in den Jahren 1908-1910: $300 \mathrm{~g}, 1910-1913: 307 \mathrm{~g}$. Wir haben es hier also mit einem ganz vorzüglichen Rassefisch zu tun, welcher an Raschwïchsigkeit in anderen Alpenseen nur vom Wildfangsaibling übertroffen werden kann.

Die natürliche Fortpflanzung des Saiblings im Grundlsee ist eine sch. rege; das Laichen erfolgt in der Regel über den Schotterbänken der Schar und Halde (in einer Tiefe von 6-40 m), an denen das Litorale des Sees am Nord- und Südufer so überaus reich ist. Die Laichzeit erstreckt sich auf die Monate Oktober bis Jänner. Außer diesen „Strandlaichern" gibt es noch "Grundlaicher", die unmittelbar in den kalten Tiefen des Sees ihre Eier ablegen. Zu letzteren zählen besonders ältere Fische, welche sich auch in anderer Bezielung von den jüngeren Artgenossen unterscheiden, indem sie nämlich in der Regel Raubfische sind, während der Durchschnitts-Saibling des Grundlsees ein typischer Friedfisch ist. Die Ernährung des Seesaiblings in den einzelnen Alpenseen ist sehr verschieden. In vielen Seen ist man geneigt, den Fisch als Raubfisch hinzustellen, der sich von kleineren Fischen wie Weißfischen usw. ernährt. In einzelnen. Seen hat man ihn als eifrigen Verzehrer der Bodenfauna erkannt, in einigen Fällen ist aber auch eine rein planktonische Ernährung festgestellt worden. So berichtet dariber Vogt folgendermaßen: "Häufig findet man selbst bei großen Saiblingen den Magen nur mit jenen durchsichtigen Krustentieren (Daphniden und Cyclopiden) exfüllt, welche auch die Speise der Felehen bilden." Über dic Eirnährung des Grundlsee-Saiblings gibt nachfolgendes Verzeichnis Aufschluls. Zur Untersuchung gelangten 23 Exemplare von $24-35 \mathrm{~cm}$ Länge aus den Jahren 1910-1914, davon 12 Männchen und 11 Weibchen. 
Zur Kenntnis einiger Alpenseen.

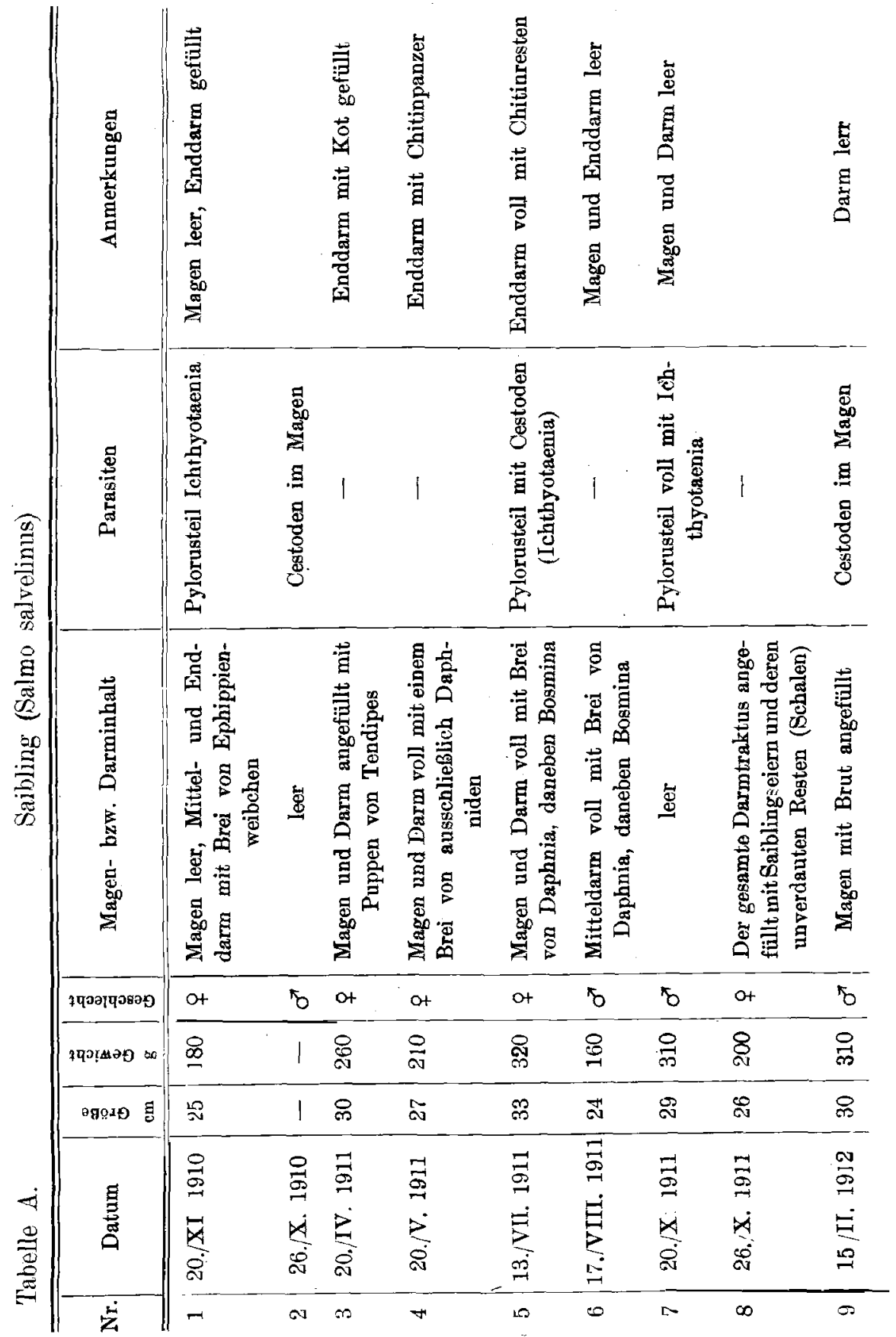


O. Haempel.

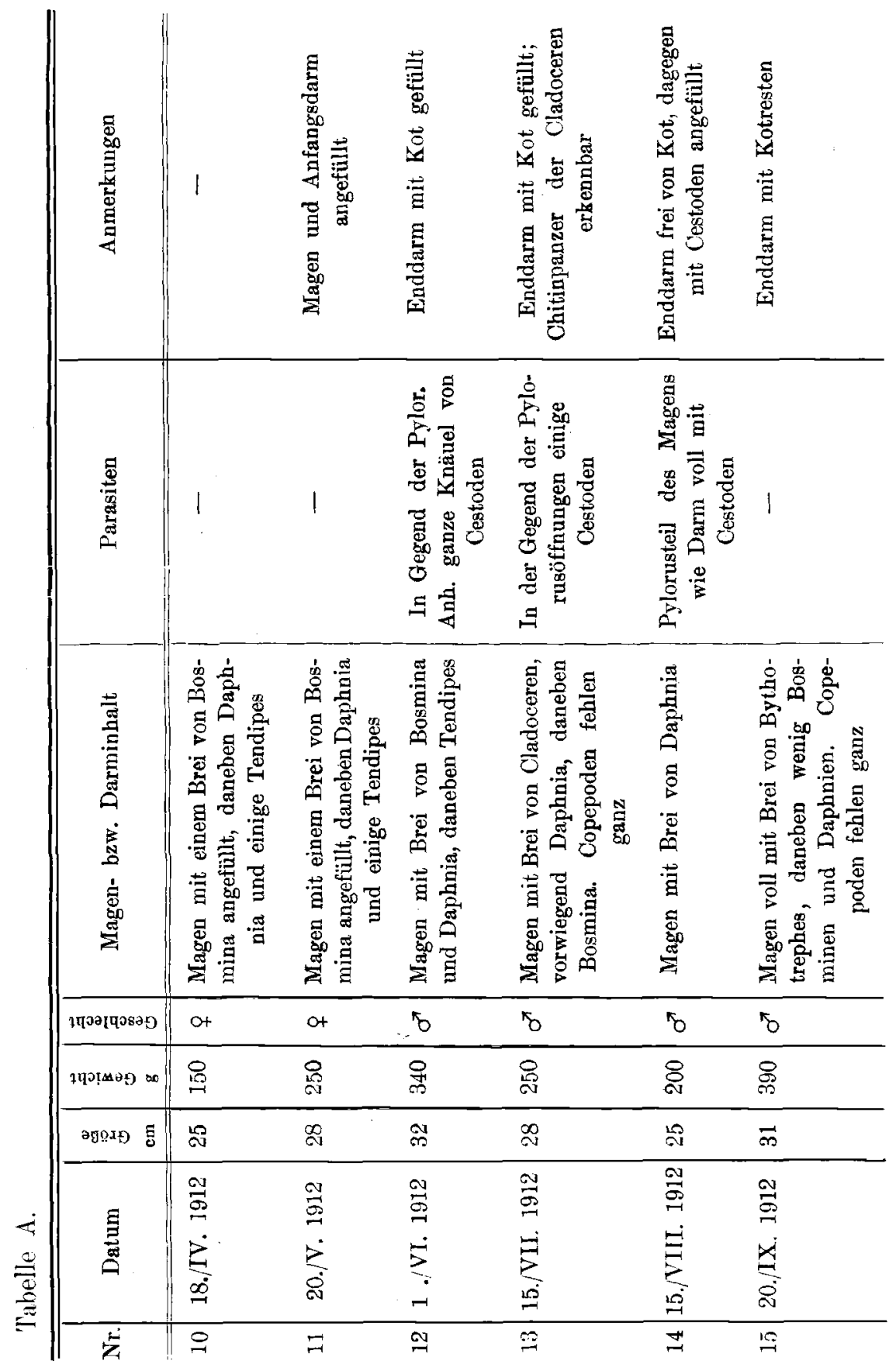




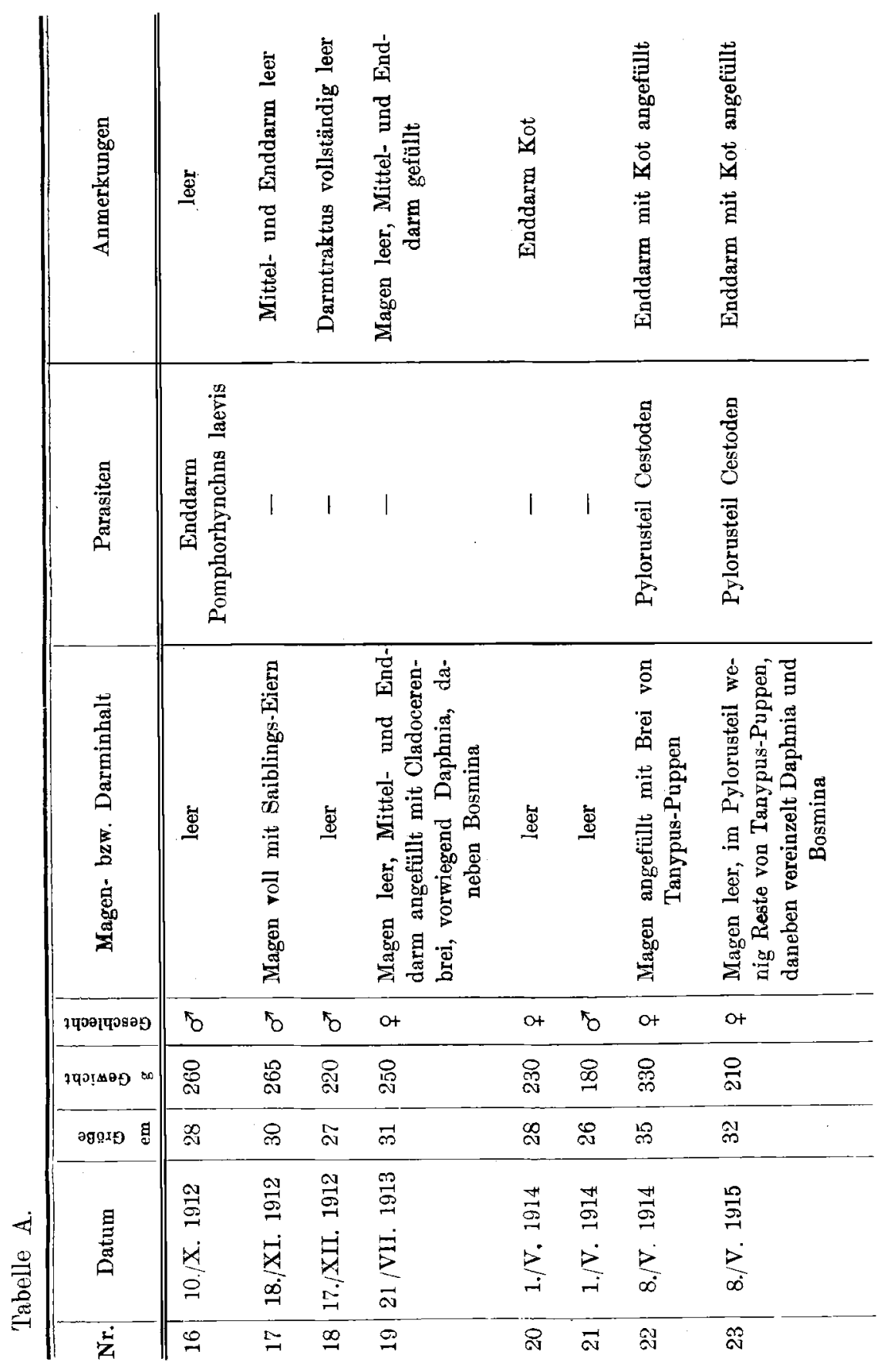


Von den untersuchten Exemplaren hatten sechs einen vollkommen leeren Darmtraktus aufzuweisen. Das findet seine Erklärung dadurch, daß die Mehrzahl derselben während und kurz vor der Laichzeit gefangen wurden, zu einer: Zeit, während welcher bekanntlich die Salmoniden fast kein Futter zu sich nehmen. Die übrigen 17 Exemplare hatten Magen und Darm meist prall angefüllt. Von diesen enthielten 2 Saiblinge (Nr. 8 und 17) viel Saiblingseier, ein Exemplar (Nr. 9) junge Saiblingsbrut. Die meisten der untersuchten Fische hatten dagegen in ihrem Magen und Darm einen dicken Brei von Daphnia aufzuweisen (Nr. 1, 4, 5, 6, 13, 14, 19) und einige ( $\mathrm{Nr} .10,11,12)$ einen solchen von Bosmina. Bei einem Exemplar (Nr. 15, Tiefenfisch!) bestand dor Mageninhalt ferner in der Hauptsache aus einem Brei von Bythotrephes, dem Daphnien und Bosminen in geringer Anzahl beigemischt waren. Schließlich hatten 3 Exemplare (Nr. 3, 22, 23) fast ausschließlich Dipterenpuppen von Tanypus und der Orthocladiusgruppe gefressen. Auffallend ist es, daß bei keinem der untersuchten Fische Copepoden (Diaptomus oder Cyclops) vorgefunden werden konnten. Aus obigen Befunden muß der Saibling des Grundlsees als typischer Planktonfresser bezeichnet werden, mit der Einschränkung, daß nur Cladoceren aufgenommen werden. Vergleicht man die Planktonkalender der Jahre 1911 und 1912 in ihrer Zusammensetzung mit den Darmbefunden der in den gleichen Monaten gefangenen Fische, so zeigt sich eine vollständige Übereinstimmung. In jenen Monaten, in denen Daphnia dominiert, wird diese in Massen aufgenommen, das gleiche gilt von Bosmina. Dagegen greifen die Saiblinge in jenen Monaten, in denen Cladoceren noch selten sind (März-Mai), zu Dipterenpuppen, die in Aufwanderung vom Seegrunde zur Oberfläche begriffen sind. Nirmals kounten Fischreste, die von gefressenen Mairenken oder Lauben stammen, gefunden werden, was auch mit den praktischen Erfahrungen der Fischer gut überejnstimmt. Nur bei den Spätlaichern, die vereinzelt noch gegen Mitte Februar auf den Laichplätzen erseheinen, kommt es vor, daß sie die von den Laichfischen Ende Oktober oder November abgesetzten Eier und Brut fressen und dadurch zu Kannibalen werden. Werden die Saiblinge des Grundlsees nach obigen Ausführungen als typische Planktonkonsumenten charaliterisiert, so ist, ähnlich wie dies bei Besprechung der Reinankenzucht im Hallstätter See geschah, vom fischereilich-wirtschaftlichen Standpunkte die Frage berechtigt, ob der Grundlsee in bezug auf Plankton so viel Nährmaterial. hervorbringt, daß die Saiblinge sowohl binsichtlich des Gesamtzuwachses als auch des Stück- 
zuwachses vollständig den an sie gestellten Anforderungen entsprechen. Auch hier muß die Frage bejaht werden. Wie aus den quantitativen Untersuchungen hervorgeht, gehört der Grundlsee unter den kalten Alpenseen zweifellos zu den planktonreichsten und wird darin nur von den warmen Kärntner Seen noch übertroffen. In den Sommermonaten werden derartige Mengen von Plankton erzeugt, daß ein nur wenige Meter dahinstreifendes Netz einen ganzen Brei zutage fördert. Dieser Planktonreichtum, man könnte sagen Planktonüberfluß, kann von den Saiblingen des Sees nicht ausgenützt wcrden, hier ist, wie wir später sehen werden, die Einführung eines weiteren Planktonkonsumenten nur am Platze. Der Planktonreichtum des Sees kommt auch schon in dem hohen durchschnittlichen Stïckgewicht der Saiblinge zum Ausdrueke.

Mit der Erkenntnis, daß die Grundlsee-Saiblinge Planktonfresser sind, tancht anch die Frage auf, ob die Fische, ähnlich wie dies für die Reinanke des Hallstätter Sees gilt, den täglichen wie jahreszeitlichen vertikalen Wanderungen des Planktons folgen. Leider liegen mir selbst darüber keine Beobachtungen zugrunde, doch scheint nach Aussage auf Grund langjähriger Erfahrungen des beeideten Grundlsee-Fischereipersonales sich diese Vermutung zu bestätigen. Zü Schlusse sei noch erwähnt, daß der Grundlsee-Saibling als Planktonfresser in krassem Gegensatze zu dem des allerdings planktonarmen Faistenauer Hintersees bei Salzburg steht; denn bei letzterem konnte Micoletzky als Hauptnahrung während des Hochsommers nur Tendipes-Larven nachweisen, als Gelegenheitsnahırung Phyllopoden, Gammariden, Ephemeriden und Neuropterenlarven. Durch die Aufnahme dieser Nahrung charakterisiert sich dieser Fisch als Grundfisch, während der Grundlsee-Saibling infolge seiner planktonischen Ernäbrung - die Tendipes-Puppen werden im Auftriebe aufgenommen - ein ausgesprochener pelagischer Seebewohner ist.

2. Die Bachforelle (Trutta fario L.) ist im Grundlsee nicht sehr häufig. Ihre Lieblingsstandplätze sind die Schotterbänke bei Einmündung der Seezuflüsse sowie die flutenden Fontinalis- und PotamogetonRasen beim Austritte der Traun aus dem See. Die reinrassige Bachforelle wächst hier gut $a b$ und erreicht ein Durchschnittsgewicht von 250 g. Um einen Einblick in die von ilr aufgenommene Nahrung zu erhalten, habe ich im ganzen 15 Exemplare untersucht, deren Magen und Darminhalt im nachfolgenden Verzeichnis zum Ausdrucke kommt (Tabelle B).

Die Hauptnahrang der Bachforelle besteht im Grundlsee aus sog. Flugnabrung d. s. Imagines ron Coleopteren, Hymenopteren und anderen 
O. Haempel.

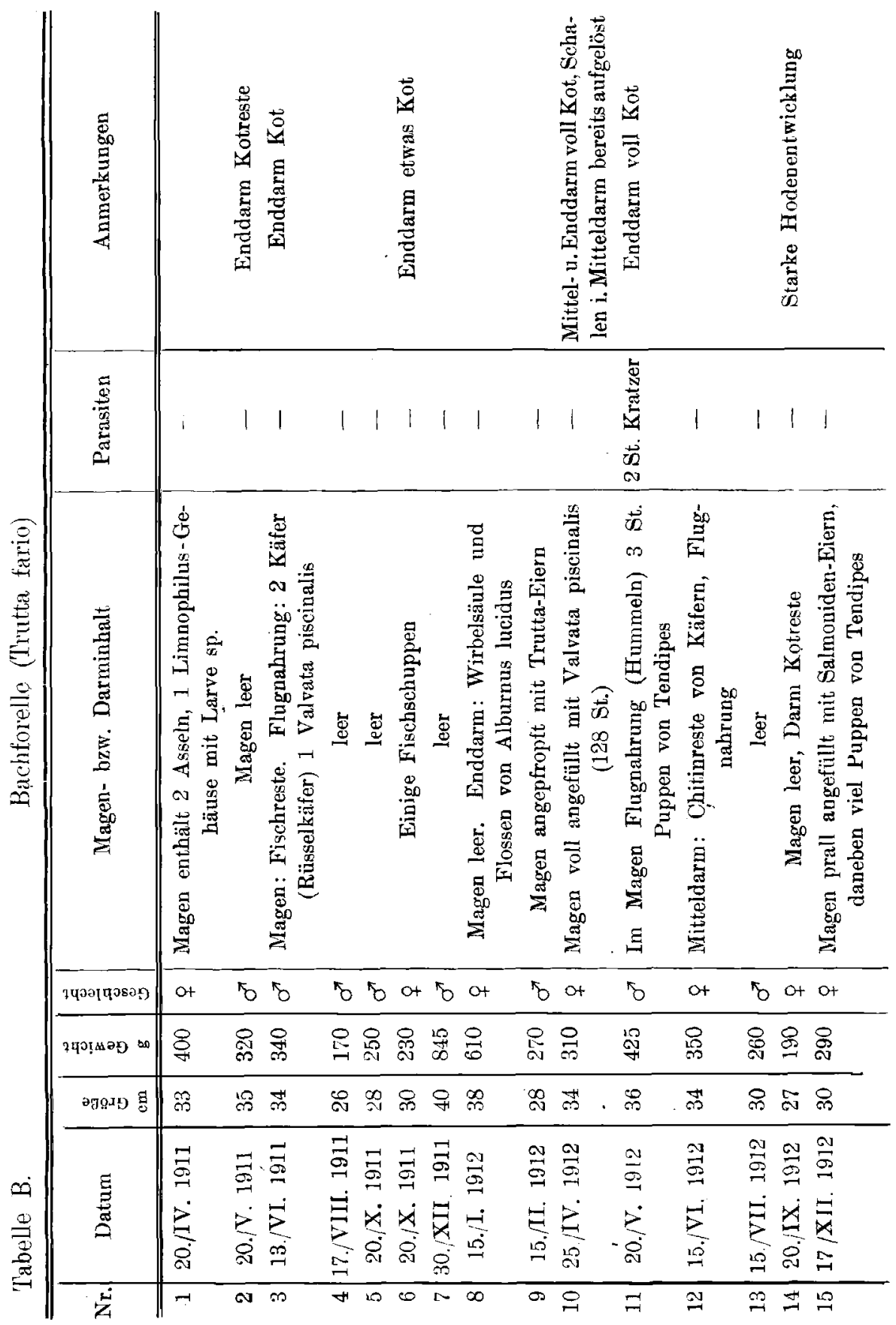


Insekten. Daneben werden auch Tendipediden- und Trichopterenlarven gerne verzehrt. Ein Exemplar (Nr. 10) hatte fast lauter Valvata piscinalis (148 St.) aufgenommen. Als Räuber, die entweder eigenen Laich oder Weißfische (Lauben) verschlungen hatten, wurden drei Exemplare angetroffen.

Die Bachforelle ist im Grundlsee ein Standfisch. Ihre Eigenschaft, die Litoralfauna des Sees auszunützen, läßt ihre Zucht im See begründet erscheinen. Doch spricht auf der anderen Seite eine noch bei der Seeforelle näher zu erörternde Eigenschaft gegen ihre Weiterzucht.

3. Die Se eforelle (Trutta lacustris) wird im Grundlsee ebenfalls in den beiden Formen als Schweb- und Grundforelle angetroffen, doch überwiegt letztere an Zahl die erstere. Dieso Form wird bis $20 \mathrm{~kg}$ schwer; Exemplare von 8-14 kg werden jährlich häufig gefangen. Der Grundlseefisch besitzt im Vergleich zur Seeforelle des Millstätter Sees ein breitgespaltenes Maul und einen weiten Schlund, wodurch er instand gesetzt wird, größere Fische wie Mairenken und Saiblinge aufzunehmen. In der Jugend nährt sich die Seeforelle des Grundlsees vorzugsweise von Anflugnahrung und Gammariden. Ein $25 \mathrm{~cm}$ langes Exemplar hatte den Magen augefüllt mit Perliden-Imagines und Gammarus pulex. Ein zweites, $35 \mathrm{~cm}$ langes Weibchen von $1 / 2 \mathrm{~kg}$ Gewicht hatte neben 7 Stück Gammarus bereits 10 Stück $5--6 \mathrm{~cm}$ lange Lauben aufgenommen. Bei diesem Fische vollzieht sich bereits der Übergang von Fried- zu Raubfisch. Schließlich kam ein $2 \mathrm{~kg}$ schweres Exemplar zur Untersuchung, welches im Magen die halbverdauten Reste von 2 Mairenken (Alburnus mento Ag) besaß. Die Seeforelle des Grundlsees zieht zur Laichzeit meist in den TraunfluB, laicht bei Niederwasserstand des Sees auch oft auf kiesigen Stellen vor dem Seeausflusse.

Wo, wie im Grundlsee, die Seeforelle mit der Bachforelle vergesellschaftet vorkommt, entstehen neben reinrassigen Formen auf natürlichem Wege auch Kreuzungen beider Fischarten, die wieder nach allen Richtungen bin fruchtbar sind. Der Bastard, der das Grundkolorit der Seeforelle mit den roten Flecken der Bachforelle verbindet, zeigt indes bereits vielfach sehr starke Degenerationsercheinungen, wie einen großen Kopf und einen dünnen muskelschwachen Körper. Meist schlägt der Forellencharakter durch. Mit Rücksicht auf diesen Übelstand entsteht die Frage, welcher von beiden Fischen im Hinblick auf eine rationelle Bewirtschaftung des Sees aus diesem zu entfernen ist bzw. welcher allein weitergezüchtet werden kann. Die Frage muß zugunsten der Seeforelle beantwortet werden. Da wir den Saibling des Grundlsees als einen Fried- 
fisch kennen gelernt haben, der die Weilfischbestände des Sees nicht ausnützt, muß ein mäßiger Raubfisch kultiviert werden, der das Fischunkraut einer'seits in wertvolles Edelfisch-Fleich umsetzt, andererseits unter den Saiblingsbeständen keinen großen Schaden anrichtet. Diesen Bedingungen entspricht einzig und allein die Seeforelle, welche dank ibrer pelagischen wie teilweise limnetischen Lebonsweise dem Fischunkraut nachstellt und selbst einen hohen Marktwert besitzt. Bei der Pflege der Seeforelle erwächst allerdings die Aufgabe, alle schwereren Fixemplare als $5 \mathrm{~kg}$ durch intensiven Ansfang aus dem See zu entfernen, da diese den Saiblingsbeständen gefährlich werden könnten.

4. Die Rutte (Lota vulgaris Cuv.), von welcher im Grundlsee größtenteils nur kleinere, im Durchschnittsgewichte von $150 \mathrm{~g}$ schwere Exemplare gefangen werden, ist wie im Hallstätter See auch hier der berüchtigste Tiefenraubfisch und Laichräuber, welcher mit allen zu Gebote stehenden bzw. anwendbaren Mitteln auszurotten wäre. Zur Untersuchung gelangten, wie nachfolgende Tabelle zeigt, 10 Exemplare (Tabelle C).

Von den untersuchten Fischen enthielten vier Exemplare den Magen nit Saiblingseiern angefüllt, bei drei weiteren enthielt der Magen die un- oder halbverdauten Reste von Fischen, von denen Koppen und Pfrillen mit Sicherheit bestimmt werden konnten. Saiblingsbrut- oder Jungfische konnten nicht vorgefunden werden, aber es unterliegt keinem Zweifel, daß auch diese in Mengen vertilgt werden. Neben diesen typischen Raubfischen waren unter den zur Untersuchung gelangten Exemplaren auch drei Stück (Nr. 1, 2, 4) vorbanden, welche nur Wirbellose aufgenommen hatten. Doch bildet diese Nahrung nur eine Celegenheitsnahrung und wird meist nur da konsumiert, wo sie massenhaft erreichbar ist.

Als Komponent der Grundlseer Fischfauna ist ferner ein Vertreter zu nennen, welcher aber wegen seines geringen Vorkommens für die Seefischerei von untergeordneter Bedeutung ist. Es ist dies der Koppen (Cottus gobio L.), ein kleiner lichtscheuer Grundfisch der Litoralregion, welcher hüchstens als Köderfisch in Betracht kommt. Erhöhte Bedeutung im Haushalte des Sees gewinnen dagegen die eingangs genannten Cypriniden wie Aitel (Squalius cephalus L.), Laube (Alburnus lucidus Heck.); Mairenke (Alburnus mento Ag.) und Pfrille (Phoxinus laevis Ag). Sie sind meist Uferbewohner, leben aber zum Teil auch pelagisch. Dies gilt besonders von der Laube und Mairenke. Die Laube ist ein Oberflächenfisch, der sich im Grundlsee bisher nicht gut eingebürgert hat, so daß ihm im Haushalt des Sees keine besondere Rolle zufällt. 
Zur Kenntnis einiger Alpensecn.

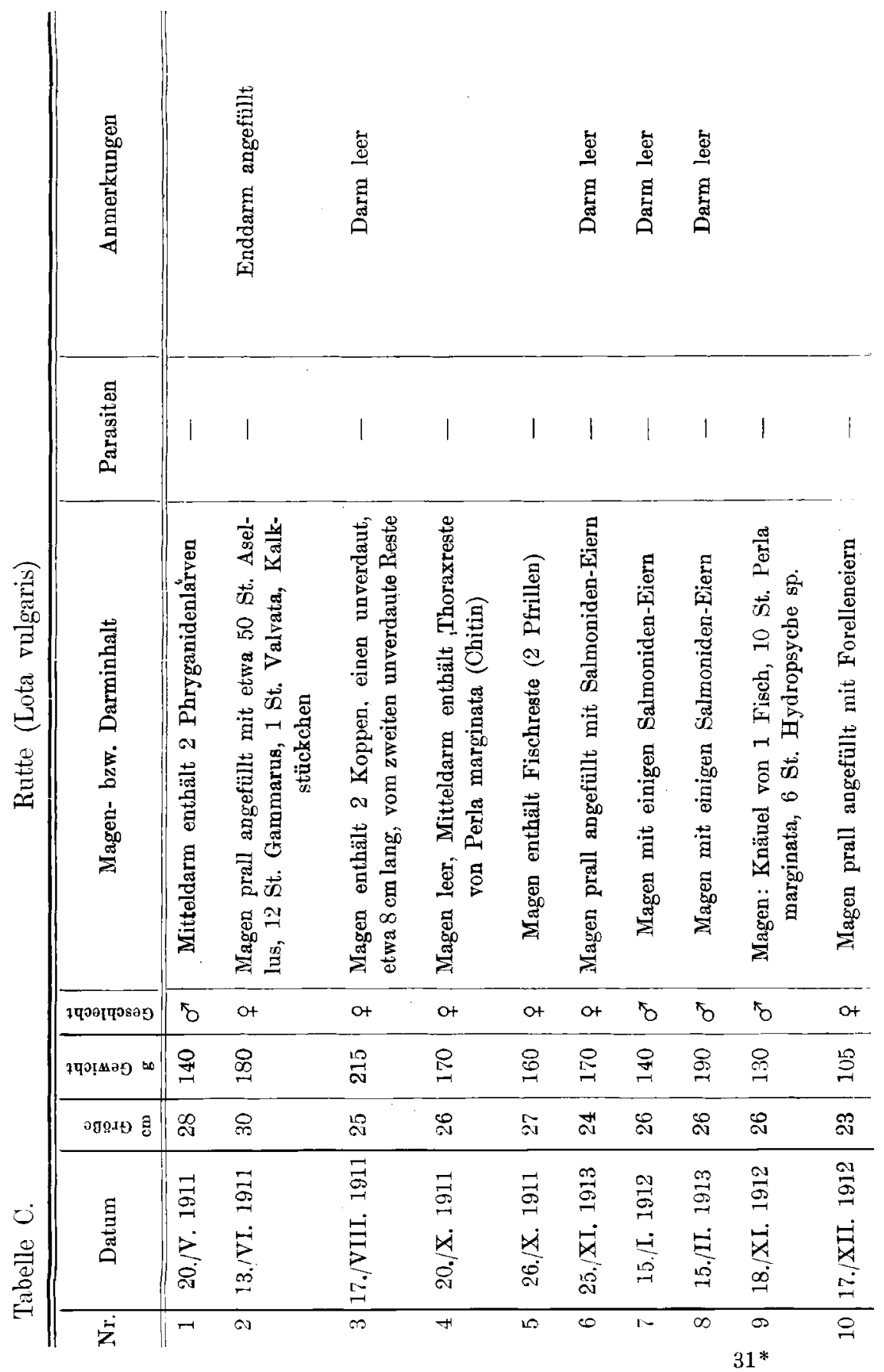


Eine erhöhte Bedeutung gewinnt dagegen die Mailenke. Sie ist dic größte Laubenart der Alpenseen und erreicht im Grundlsee eine Länge bis etwa $25 \mathrm{~cm}$. Von der Laube, mit der sie das lebhafte Gebaren und das Auftreten in Schwärmen gemein hat, unterscheidet sie sich leicht durch den gestreckten Körper und die hinter der Rückenflosse ansetzende Afterfosse. Sie ist, wie das kurze Verzeichnis D zeigt, ein typischer Planktonkonsument, der besonders Bosmina zu bevorzugen scheint.

Tabelle D. Mairenke (Alburnus mento)

\begin{tabular}{|c|c|c|c|c|c|c|}
\hline Nr. & Datum & 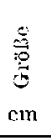 & 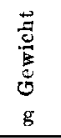 & 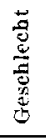 & Magen- bzw. Darminhalt & 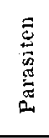 \\
\hline 1 & 13./VI. 1911 & 22 & 55 & $q$ & $\begin{array}{l}\text { Magenteil leer, Darm Chitinreste } \\
\text { einer Flugnabrung, } 1 \text { Assel }\end{array}$ & - \\
\hline 2 & 15./SII. 1912 & 19 & 75 & 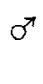 & $\begin{array}{c}\text { Darmtraktus gefïllt mit Bos- } \\
\text { minenbrei }\end{array}$ & - \\
\hline 3 & 17./VIII. 1911 & 21 & 100 & q & $\begin{array}{c}\text { Darmtraktus prall gefüllt mit } \\
\text { Bosminenbrei, daneben vereinzelt } \\
\text { Daphnia und Cyclops }\end{array}$ & - \\
\hline 4 & 26./X. 1911 & 15 & 60 & $q$ & Darn gefüllt mit Bosminenbrei & - \\
\hline
\end{tabular}

Infolge dieser rein planktonischen Ernährung hält sich dieser Fisch vorwiegend im Pelagial auf und wird dadurch für: die Seeforelle zum wichtigsten Futterfisch. Tatsächlich konnte ich auch im Darmitraktus einer solchen (s. S. 481) zwei größere Mairenken nachweisen.

Wirtschaftlich ist die Mairenke für den Grundlsee insofern von Bedeutung, als zu gewissen Zeiten von den Fischern große Nengen derselben erbeutet und gut verwendet werlen.

Über die übrigen den See bewobnenden Weißfische ist nicht viel zu sagen, da ihnen im Seehaushalte nur eine untergeordnete Rolle zufällt. Das Aitel ist Uferfisch und erreicht nur eine bescheidene Größe. Das gleiche gilt ron der Pfrille, die ein eifriger Verzehrer der Litoralkrebse (Chydorus, Acroperus usw.) ist. Sie konmt im Grundlsee in großen Mengen vor, findet aber leider nur eine geringfügige Verwertuny, da die ihr nachstellende Bachforelle nur einen kleinen Teil dezimiert.

Nach diesen Ausfübrungen über die im Grundlsee heimische Fischfauna, ihre Ernährung und Bedeutung im Haushalte dieses Sees obliegt 
es, die eingangs gestellten Fragen einer Betrachtung zu unterziehen. Die ersten beiden lassen sich zusammen behandeln; in Kürze wiederholt lauten sie nochmals: Welche Fischarten verdienen bei voller Berücksichtigung der floristischen und faunistischen Eigenheiten des Grundlsees und der Art der Ernäbrung der Fische einer besonderen Pflege? Kann nur ein Hauptfisch gezüchtet werden oder können nebeneinander mebrere Arten bestehen, ohne daß gegenseitig eine Schädigung erwächst, die zur Degeneration führt? Wie bereits hervorgehoben wurde, zählt der Grundlsee ähnlich wie der Hallstätter See zu den kalten Alpenseen: seine Oberflächentemperatur erreicht indes in den Sommermonaten eine höhere Temperatur $\left(20^{\circ} \mathrm{C}\right)$. Dieser Temperaturunterschied ist groß genug, un eine erhebliche quantitative Differenz in der Planktonproduktion zugunsten des Grundlsees herbeizuführen. Desgleichen spielt der Uinstand, daß der Grundlsee im Vergleich zum Hallstätter See im Verlauf des Kalenderjahres bei weitem mehr Sonnenlicht und eine schwache Strömung erhält, eine wesentliche Rolle. Diese Tatsache ist sehr wichtig, da das Sonnenkicht ja bekanntlich ein Hauptfaktor für das Wachstum der assimilierenden Pflanzen ist, also für die Grundlage aller Produktion, die Urnahrung (Nannoplankton) für alles tierische Leben. Seiner Planktonproduktion nach muß der Grundlsee in der Tat zu den "sehr guten" Seen gezählt werden; er übertrifft an Planktonquantität die in gleichen Flulggebiet liegenden Seen wie Hailstätter und Traunsee úm wesentliches. Besonders wertvoll ist die Massenproduktion ron Cladoceren, welche das Lieblingsfutter der Saiblinge des Sees bilden. Auch diese Erscheinung ist ein ganz sicheres Anzeichen dafür, daß der Grundlsee viel nahrungsreicher ist als die anderen Seen, die, wie z. B. der Hallstätter, fast das ganze Jahr ein Copepodenplankton aufweisen. Der Planktonreichtum des Grundlsees kommt in dem hohen Stückgewicht der Saiblinge dieses Sees (Durchschnittgewicht $300 \mathrm{~g}$ ) schön zum Ausdrucke. Der Saibling verdient hier als Hauptfisch auch weiterhin die intensivste Pflege. Es entsteht aber nun die Frage, ob der Planktonreichtum des Sees durch die Zucht des Saiblings als Hauptfisch entsprechend ausgenützt wird. Die Frage muß negativ beantwortet werden. Um welche Mengen von Plankton es sich hier handelt, darüber möge vergleichsweise eine Berechnung Schröters (11) zugrunde gelegt werden. Dieser konnte am 12. Mai 1896 für den Züricher See das Vorhandensein von $430 \mathrm{~kg}$ Trockensubstanz Plankton pro ha See-Fläche berechnen. Das würde nach meiner Umrechnung einer Menge von etwa 12,4 $\mathrm{m}^{3}$ Rohvolumen entsprechen! Es ist sicher, daß im Grundlsee große Mengen von Plank- 
ton-Nährstoffen der Fischwirtschaft verloren gehen. Der Ertrag des Grundlsees müßte daher durch Einbürgerung eines zweiten Friedfisches eine erhebliche Steigerung erfahren. Als solcher kommt die während des Sommers in den oberen Wasserschichten lebende Reinanke des Hallstätter Sees, über deren Vorzüge in der Monographie dieses Sees ausführlich die Rede ist (3), in Betracht, zumal dieser Fisch geejgnet ist, das P'lankton der höheren Wasserschichten besser auszunutzen als der Saibling, welcher im Hochsommer als Bewohner tieferer Schichten $(10-20 \mathrm{~m})$ das Oberflächenplankton nur bei seinen zeitweisen Wanderungen nach aufwärts konsumiert. Von der Reinanke ist eine wesentliche Störung der Saiblinge in ihrem Laichgeschäft oder eine sonstige nennenswerte Schädigung des Saiblingsbestandes nicht zu erwarten. Denn die Reinanken des Hallstätter Sees wandern zum Laichen zum großen Teile in die Traun oder legen die Eier im Pelagial ab, während die Saiblinge die Schotterbänke der Uferschar zu diesem Zwecke aufsuchen. Es sei kurz erwähnt, daß über Anregung des Verf. seit Anfang 1914 Brütlinge der Hallstätter Reinanke im Grundlsee bereits eingesetzt wurden; über den Erfolg wird später berichtet werden. Noch eine zweite Frage entsteht: Wäre es nicht von Vorteil, in den Grundlsee noch eine zweite Coregonenart einzusetzen, welche als T'iefenhewohner die Fauna des Seehodens anszunützen vermag! Hier käme natürlich nur eine Bodenrenke, wie sie die Bodenrenkedes Attejsees (Coregonus fera Jur.) oder die Peipusseemaräne (Coregonus maraena Bl.) repräsentieren, in Betracht. (Siehe Hallstätter See-Arbeit l. c.). Rein theoretisch betrachtet wäre eine solche Ausnützung des Sees das Ideal. Doch scheinen mir gegen eine Besetzung mit obigen Fischen zwei Gründe zu sprechen. Dex eine wäre der, daß von diesen beiden Tiefenrenken die Attersee-Bodonrenke möglicherweise dieselben Laichplätze wie die Saiblinge aufsucht, dadurch also cine Verdrängung des wirtschaftlich wertvolleren Fisches stattfinden kö̈nnte; der andere, daß sich beide Fische mit zunehmender Größe zum Raubfisch entwickeln, und als Laich- und Brutrüuber unter den Saiblingen einen großen Schaden anrichten kömnen. Dem ist allerdings entgegenzuhalten, daß auf der anderen Seite auch ein starker Coregonenbestand im Grundlsee nicht annäherud soviel schaden stiften kann wie die räuberischen Rutten, deren im See jedes Jahr eine nicht unbeträchtliche Menge gèfangen wirrl. Wenn man endlich nach Aussage des Fischerei-Inspektors von einer Besetzung des Grundisees mit einer Bodenrenke bisher abgesehen hat, so geschah dies in der Erkenntnis, daß der See für einen günstigen 
Bestand an Saiblingen - des wertrollsten Tiefenfisches - noch selir entwicklungsfähig ist.

Mit obigen Ausführungen sind in Kürze die wichtigsten Punkte für eine rationelle fischereiliche Acisnutzung des Grundlsees, soweit sie das Resultat hydrographisch-biologischer Untcrsuchungen sind, angeführt. Die gegenwärtige Bewirtschaftung des Sees ist als mustergültig zu bezeichnen und Verdienst des Fischerci-Inspeltors E. Doljan sowie der mehrfach erwähnten Forst- und Domänenrerwaltung Grundlsee in Aussee, welch letztere das Fischereipersonal beistellt und überwacht. Der See ist in seiner Gänze staatliches Fischerci-Eigentum und wird mit einem Fischmeister und zwei ständigen Hilfskräften rationell bewirtschaftet. Die Bewirtschaftung besteht aus zwei Phasen: dem Ausfang und Verkanf der Saiblinge und Secforcllen und der. Neubesetzung des Sees mit Jungfisehen (Brütlingen und einsömmrigen Setzlingen) dieser Arten. Von einer Beschreibung des Fanges mit Zugnetzen usw. möchte ich an dieser Stclle absehen; es sei nur erwähnt, daß derselbe unter strengster Berücksichtigung der Minimalmaße ausgeiibt wird. Die Fischereirerwaltung geht in dieser Frage noch einen schritt weiter; während in Steiernark sonst für den Saibling ein Minimalmaß ron $25 \mathrm{~cm}$ bei einem Durchschnittgewicht von $160-200 \mathrm{~g}$ rorgeschrieben ist, wird in Grundlsee jeder Fisch, welcher nicht mindestens $250 \mathrm{~g}$ Gewicht erreicht hat, wieder dem See zurückgegeben, so daß das durchschnittliche JahresStückgewicht schon seit längerer Zeit $300 \mathrm{~g}$ beträgt. Desgleichen findet nach züchterischen Gesichtspunkten eine sorgfältige Auslese aller gefangenen degenerierten Exemplare (großer Kopf, geringe Körperhöhe, spindelförmiger Leib) statt. Auch wird zur Blutauffrischung Zuchtmaterial aus dem Faistenauer Hintersee herangezogen. Auf Grund sorgfältiger Zuchtwahıl ist es in den letzten Jahren grelungen, eine hochwertige Rasse im See zu züchten. Die alljährliche Besetzmng des Sces erfolgt mit Jungfischen ron Seeforellen und Saiblingen, die in der Brutanstalt "Grundl-

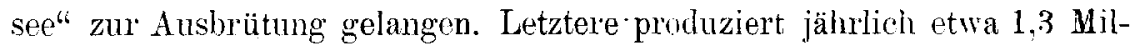
lionen Salmoniden-Brütlinge und ist mit einer Eiauflage von mehr als 1 Million Saiblingseiern die größte österreichische Saiblings-Zuchtanstalt. Dank dieser Aussetzung ist es gelungen, den (rrundlsce zu einem der fischereilich ertragreichsten Alpenseen zu gestalten. Es sei nur kurz erwähnt, daß sich der jährliche Durchschnittsertrag an Naiblingen mit $4-5 \mathrm{~kg}$ pro ha Seefläche berechnen läßt. 


\section{Zusammenfassung der wichtigsten biologischen und fischerei- lichen Ergebnisse der Untersuchung.}

1. Der (Firundlsee weist init Rücksicht anf seine Lage, l'iefe und 'len)peratur den Charakter eines Kaltwassersecs der Ostalpen anf. In den heißen Sommermonaten kaun indes die Oberflächentemperatur die Hïhe von $20^{\circ} \mathrm{C}$. und darüber errcichen.

2. Der Ifferahfall zur 'Jiefe ist an den beiden Längsseiten, mit Ausnahmo: zweier Stellen ein sanfter. Fine tlache Uferschar, mit grobem Nteingerijlle beleckt, ist gut ausg(-3ildet. Das Ost- und Westencle des: sees liunt ebenfalls tlach aus.

3. Der Uforgestaltung low. Cforauskleidung zufolge ist die Entfaltung der hibleren Flora eine geringe. Sie ist mit $i$ Arten vertroten. Dio nicder Flora ist artemeich.

4. Infolge der Florenarmut lï̈men wir in Litorale des Sietes nur 3 Zonen unterscheiclen. Es sind dies: 1. dic .Zone des Stein-Creü̈ls; 2. die \%one des Potanogetons (Potamugotonetum); 3. die Zone der Chara. wiesen (Characetum).

5. Die Futwicklung der Litoralfauna ist eine reiche und verteilt sich ant dic genannten drei Zomen. Die Listo umfalit ohne Wirbelticre ungefähı 63 Arten.

6. Die Grundfauma ist antenam, dagegen in bezug atuf 'TendipendidenLarven und Molluslien individuentrich.

7. Das Mikroplankton cuthält die für dit: Ostalpenseen charaliteristischen Fumen. Das Ter\%eichnis zählt 9 Plịto- und 19 Zooplanktonten auf. Im Phytoplankton dominieren anch bier dic Diatomeen. Das Zooplanlitom ist toils ein Copepoden-. teils cin Cladocorenplankton. Wäbrend ersteres rom Febınar bis Juni dominiert. ist letztejes während cler Sommermonate bis in den spätherbst ronherrscluend. In den Monat. Jänner fällt tin Maximum ron Bosmina. Riilerticre sind bis auf Asplanchna in Monat Dezember nicht häufig.

8. Die meisten Vertreter des Planktons sind perrennierend. Daphinia Iyalina, Bythotrepbes und Leptodora sind monozsklisch und rerschwinden für cinige Monate vollständig aus dem Plankton. Bosmina coregoni hingegen ist pereunierend und erzengt Männchen und Ephippien. Damit ist die Ansicbt von der partlenogenetischen Furtptlanzung alpiner Busminen endgültig widerlegt. Die Copepoilen sind prorennicrend und bilden z.wei Jahres-Maxima. 
9. Eine rertikale Schichtung des Gesamtplanktons im see ist nachweisbar. Die Oberflächenschichten bis $3 \mathrm{~m}$ enthalten in Sommer rorwiegend Flagellaten (Dinobryon und Ceratimm), zwischen 3-10 m findet sich die größte Anbäufung der Cladoceren (Daphnia und Bosmina) und zwischen 10-40 $\mathrm{m}$ überwiegen die Copepoden (Diaptomus und Cyclops). Triarthra ist typische Tiefenform. In quantitativer Hinsicht rangiert der Grundlsee zu den planktomreichen oder fischereilich "sehr guten“ Seen.

10. Die horizontale Verteilung des Planlitons im See ist eine gleichmäßige, die Erschcinung einer Uferflucht angedeutet.

11. Eine gut ansgeprägte Temporalvariation fehlt den meisten Planktonten des Grundlsees; sie konnte eigentlich nur für Bosmina coregoni nachgewiesen werden, doch läßt sich die Richtung der Tariation nur schwer in Beziehung zum Gang der Temperatur setzen.

12. Der Grundlsee cuthält 9 Arten von Fischen, von denen 5 Raubfische und 4 Friedfische repräsentieren. Ölologisch stehen 6 Uferfischen 2 pelagische und 2 Tiefenbewohner gegenüber.

13. Der Hauptmitaungstisch ist der Saibling (Salmo salrelinus L.), in zweiter Linie die Seeforelle (Trutta lacustris L.). Als Nebenfische sind Bachforelle (Trutta fario L.) und die Weilfische ron gewisser tischereilicher Bedeutung. Schädlich und ans dem See durch schonungslosen Fang zu entfernen ist die Rutte (Lota vulgaris Cuv.).

14. Der Saibling des Grundlsees ist typischer Planktonfresser, die Seeforelle Vertilgerin der Lauben, Mairenkenschwärme und Saiblinge. Beide Fische können im See gut nebeneinander bestehen, wenn der Seeforellenbestand ein heseheidenes Maß nicht überschreitet und die großen Exemplare eifrig. ansgefangen werden.

15. Dem Grundlsee fehlt zur vollständigen Nahrungsausnützung ein zweiter Planktonkonsument. Als solcher konmt die Reinanke des Hallstätter Sees (Coregonus steindachneri) in Betracht, welche eine schnellwüchsige, stenotherme Form repräsentiert. Zur Ausnutzung der Bodenoder Grundfauna wäre die Einbürgerung der Attersee-Bodenrenke (Coregonus fera) oder der l'eipusseemaräne (Coregonus maraena Bl.) in Erwägung zu ziehen. 


\section{Literatur.}

Die hier angeführte Literatur bezieht sich meist nur anf den Grundlsee. Eine ausführliche Literaturangabe über Alpenseen findet sich in der Arbeit über den Hallstätter See, s. diese Zeitschrift Bd. VIII, Heft 3.

1. Brehm, V., Útersuchungen über das Plankton des Erlaufsees. Verhandlungen der zoolog. botan. Ges. Wien 1902.

2. Brehm, V., Zusammensetzung, Verteilung und Periodizität des Zooplanktons im Achensee. Zeitschr. d. Ferdinandeums III. Folge, H. 46. 1902.

3. Haempel, 0., Zur Kenntnis einiger Alpenseen. I. Der Hallstätter See. Intern. Revue d. ges. Hydrob. und Hydrogr. Bd. VIII, H. 3. 1915.

4. Langhans, v., Clacloceren aus dem Salzkammergut. Lotos Bd. 59. 1911.

5. Micoletzky, H., Zur Kenntnis des Faistenauer Hintersees bei Salzburg. Intern. Rev. Bd. III. 1910-1911.

6. Micoletzky, H., Freilebende Süßwasser-Nematoden der Ostalpen. Zool. Jahrb. Syst. Bd. 38, H. 3/4. 1914.

7. Müllner, J., Die Seen des Salzkammergutes. Erläuterungen z. ersten Lieferung d. öst. Seenatlasses. $1 \varangle 96$.

8. Richter. E., Atlas der österr. Alpenseen.

9. Rühe, F. E., Beitrag zur Biologie der Bosminen des Salzkammergutes. Archiv f. Hydr. u. Planktonkunde. Bd. 10, H. 1. 1914.

10. Schiemenz, P., Über die Nahrung unserer gewöhnlichen Wildfische. Deutsche Fisch.-Zlg. 1905.

11. Schröler, C., Die Schwebeflora unserer Seen. Naturf. Ges. Zürich 1896.

12. Vogt-Hofer, B., Die Süßwasserfische von Mitteleuropa. Leipzig 1909. 